\title{
The Hidden Semantics of Time: to adore implicitly lasts longer than to bite
}

\author{
Thiago Oliveira da Motta Sampaio*1, Virginie van Wassenhove ${ }^{* 2}$ \\ ${ }^{1}$ Instituto de Estudos da Linguagem, UNICAMP, Rua Sérgio Buarque de Holanda 571, 13.083-859 \\ Campinas, Brazil ; ${ }^{2}$ Cognitive Neuroimaging Unit, CEA DRF/Joliot, INSERM, Université Paris-Sud, \\ Université Paris-Saclay, NeuroSpin center, 91191 Gif-sur-Yvette, France
}

\author{
*Corresponding Authors: \\ Thiago Oliveira da Motta Sampaio \\ thiagomotta@iel.unicamp.br \\ Virginie van Wassenhove \\ Virginie.van.wassenhove@gmail.com
}

\begin{abstract}
Does to sneeze or to age implicitly convey the time scales at which we experience these events? To age appears to capture a persistent or durative state in life, whereas to sneeze appears more punctual in time. We tested whether the meaning of verbs, outside of discourse or sentential context, implicitly convey an inner sense of time. We used a series of categorization tasks to evaluate the implicit associations of verb meaning with psychological duration. Participants categorized verbs according to their linguistic aspect (punctual/durative) and according to four timeframes (temporal categorization). Last, we tested the association between linguistic aspect and psychological timeframes. We report reliable aspectual and temporal categorizations of verbs and, crucially, implicit associations between aspect and timeframe. Our findings suggest that outside sentential contexts, verbs implicitly convey timing information. These results have important implications for the understudied semantics and conceptual aspects of time in Human psychology and psycholinguistics.
\end{abstract}

\section{Highlights}

- Using an implicit association task, we tested the psychological reality of linguistic aspect.

- Durative and punctual are valid psychological categories of verb semantics.

- Verbs are implicitly associated with timeframes in absence of contextual discourse.

- Words may implicit calibrate interlocutors on common mental timeframes.

Keywords: time perception, temporal cognition, mental time line, aspect, punctual, duration, semantics, lexical, chronometry, psycholinguistics 


\section{Introduction}

The human eye converts electromagnetic energy (400 to $700 \mathrm{~nm}$ ) into visual information, which contributes to the representation of perceptual categories in the brain such as a horizontal or a vertical line, or the blue or green color of an object. Are those categories physical concepts? Linguistic relativity (Sapir-Whorf hypothesis; Kay \& Kempton, 1984) suggests that different cultures establish different category thresholds for the same physical continua: for example, Vietnamese (Nguyen, 2012) and Lakota Sioux (Ullrich, 2008) speakers do not distinguish blue and green. This is not to say that Vietnamese and Lakota Sioux do not perceive these colors, or that they see different colors than English speakers do, but they simply do not have different words for blue and for green qualities. Conversely, English and Romance languages do not share Inuits' shades of white/snow (Pullum, 1991). Humans can thus conceptualize abstract entities/events: some of them are unreal such as gnomes or unicorns, while others are unobservable directly through our senses, such as the Higgs boson or quantum entanglement. These are theoretical entities or events. The Human mind represents all abstract, theoretical, and observed events as psychological events. To communicate, these psychological events need to map onto linguistic events: such representational mechanisms implicate logical internal syntactic and semantic structures capable of being encoded in morphosyntactic dependencies, semantic relationships, and phonological forms. Some of these properties are explicit in their linguistic representations, such as the entities involved and their roles in a given action, as well as their causes and consequences (e.g., thematic and aspectual roles, in the sense of Tenny, 1992) whereas others remain implicit. All these properties combined are linguistic events (Rosen, 1999).

In this study, we explored the possibility that the meaning of words implicitly carries the experiential timeframes of events, considering that the study of semantics offers a way of investigating the human conceptual system (Evans, 2003, 2004). One way to represent an event is by experiencing and encoding it in episodic memory: in a lifetime, we experience a large set of events of the same type and generalize some of their properties into long-term memory (Knott, 2012). This may also be the case for the timing of events, and in particular for their average duration, which could be stored in semantic memory. Although such information may serve perception at large by feeding in and interfacing with time estimation, to which extent this information is accessible to the linguistics system is unclear. To understand the mapping of these representations into linguistic events, descriptive linguistics have identified some properties related to the timeframe of events. Specifically, timeframe of events can be exemplified by the existence of an inherent endpoint (telicity: 'eat an apple', in which the state 
of the apple would measure the event), by its progression (gerunds: 'eating an apple') or by its duration (punctual or durative: 'to sneeze' vs. 'to age', respectively). All these properties are called Aspect, and they are present both in the meaning of a verb - e.g., 'John sang a song' and in the meaning of its temporal context, which may provide an explicit quantification of time - e.g., 'for three minutes'.

One working hypothesis in psycholinguistics thus posit that aspectual incongruences between the verb and its temporal context can yield a forced meaning, which has been coined aspectual coercion (Jackendoff, 1997; De Swart, 1998). Another working hypothesis points to a correlation between the duration of events and their online processing: Coll-Florit \& Gennari (2011) were the first to investigate this point and to show that temporal properties of linguistic events have a direct influence on word-by-word sentence processing. In their study, they showed that sentences with durative events yielded higher reading times than sentences referring to non-durative events inserted or not into narrative contexts (e.g. to owe 50 euros $v s$. to lose 50 euros). Inflections of the same verb (e.g. covered $v s$. was covering) yielded a similar effect. The authors also tested in an offline experiment how participants judged the duration of the materials used in their previous online tests. Their results showed a correlation between the duration and the online processing times of each sentence. In their work, whether an infinitive verb alone and outside a sentential context could implicitly convey meaning about timeframes was not systematically explored.

Here, we focused on establishing, quantifying, and exploring the relation between the aspect of non-inflected verbs (time semantics) and the timeframe of events (psychological time) without contextual cues such as sentences or discourse. To assess the existence of implicit associations between verbal aspect and event timeframes, we used the Implicit Association Test (IAT; Greenwald et al, 1998), which enables to assess the strength of association between concepts so that using a response for closely related concepts would be easier than for remotely related concepts (https://implicit.harvard.edu/implicit/). We modified the IAT using a list of 60 verbs a priori classified by three independent native speakers of French as being punctual or durative (Table 1). An independent and naïve group of native French speakers tested each verb in a series of six classification tests: first, participants classified verbs as punctual or durative (Fig. 1; aspectual categorization tests $1 \& 2$ ), then as a function of their possible duration (temporal categorization tests $3 \& 4$ ). Last, we tested whether verbs classified as punctual would systematically be associated with shorter timeframes and, conversely, whether verbs classified as durative would systematically be associated with longer timeframes (association tests $5 \& 6$ ). We thus tested six series of six classifications each using four different timeframes (Fig. 1C). We show that the categorization of verbs as being punctual or durative, and their 
association with a particular timeframe, was highly and significantly consistent across participants. The clustering of verbs classified as punctual (durative) robustly matched the clustering of verbs associated with shorter (longer) timeframes. Altogether, our study suggests that semantics implicitly convey timing information, yielding novel insights on the understudied conceptual and semantic representations of time in the Human mind.

\section{Materials and Methods}

\section{Participants}

Twelve native speakers of French (18-25 y.o., 3 females), all right-handed with normal or corrected-to-normal vision participated in the experiment. All participants provided written informed consent prior to the experiment in accordance with the Ethics board of NeuroSpin (CEA, DRF/Institut Joliot) and the Declaration of Helsinki (2008).

\section{Selection of verbs}

Three native speakers of French judged a list of 60 French verbs by their aspectual properties, i.e. as punctual or durative (Table 1). As aspectual properties are not a trivial classification even for linguists, participants were instructed as follows: durative events are "perceivable events, with an easily measurable duration using the human senses" while "the duration of punctual events is not perceivable without instruments". This definition is in line with Block's definition for the subjective duration of psychological events (1990), "If an event lasts for less than a few milliseconds, it seems instantaneous - without duration. If an event or episode persists for longer than a few milliseconds, people experience, remember, and may therefore be able to judge duration". A total of 60 French verbs consisting of 30 a priori punctual verbs such as "piquer" [to sting] and 30 a priori durative verbs such as "promener" [to walk]. The 30 punctual and the 30 durative verbs were normed by their morphological neighborhood, number of phonemes (4-7), frequency (Lexique 3.8; New et al. 2001) and by their mean reaction times (RTs; Lexique 2-French Lexicon Project; New et al. 2004). Two durative verbs with 3 phonemes were also added to ensure an adequate number of stimuli.

\begin{tabular}{llll}
\hline French & & English translation & \\
\hline Punctuel & Duratif & Punctual & Durative \\
\hline acheter & adorer & to buy & to adore \\
allumer & balayer & to spark & to sweep \\
annoncer & boire & to announce & to drink \\
appuyer & chanter & to support & to sing \\
\hline
\end{tabular}




\begin{tabular}{llll}
\hline arriver & conduire & to arrive & to drive \\
asseoir & courir & to seat & to run \\
avouer & craindre & to confess & to fear \\
casser & danser & to break & to dance \\
choisir & déjeuner & to choose & to lunch \\
cogner & dîner & to knock & to dine \\
coucher & discuter & to sleep & to discuss \\
couper & dormir & to cut & to sleep \\
crier & écouter & to yell & to listen \\
déchirer & écrire & to tear & to write \\
éclater & étudier & to burst & to study \\
écraser & fêter & to crush & to celebrate \\
entrer & $*$ fumer & to enter & *to smoke \\
envoyer & habiller & to send & to dress \\
éteindre & jouer & to turn off & to play \\
exploser & laver & to explode & to wash \\
frapper & lire & to hit & to read \\
mordre & manger & to bite & to eat \\
payer & marcher & to pay & to walk \\
piquer & nager & to sting & to swim \\
plier & nettoyer & to fold & to clean \\
plonger & penser & to dive & to think \\
quitter & promener & to leave & to amble \\
sauter & $*$ raser & to jump & $*$ to shave \\
sortir & travailler & to exit & to work \\
tomber & vieillir & to fall & to age \\
\hline & & & \\
& & &
\end{tabular}

Table 1: List of verbs. Prior to the experiment, three native speakers of French independently classified each verb as durative or punctual. The implicit aspectual categorization tests $1 \& 2$ overlapped very well with this explicit classification to the exception of two verbs at the interface of two clusters indicated with *.

\section{Main experiment}

In the main experiment, participants were seated about $60 \mathrm{~cm}$ away from a 17" CRT monitor. Words were white Arial 24 font on a black background. The experiment was coded using Matlab (Mathworks 2011b for Windows (XP)) with Psychtoolbox v3 (Brainard 1997; Kleiner et al. 2007). To avoid habituation, verbs appeared between $500 \mathrm{~ms}$ and $1000 \mathrm{~ms}$ after an initial fixation point. The verb lasted for $200 \mathrm{~ms}$. Using a French AZERTY keyboard, participants were instructed to categorize as fast as possible the verb to one of the two possible categories displayed on the top left and top right corners of the screen. Participants pressed the [h] key for the category displayed on the right, the [j] key for the category on the left, or the [spacebar] if they missed the verb or did not have an answer. The experiment was built on the basis of the Implicit Association Test (IAT) consisting of testing, by means of chronometric measurements, the possible implicit associations between two concepts (Greenwald et al 1998, 2007). Here, we adapted the original IAT to ask whether the semantics of verb implicitly included the most probable duration or time frame of the given action. 
A

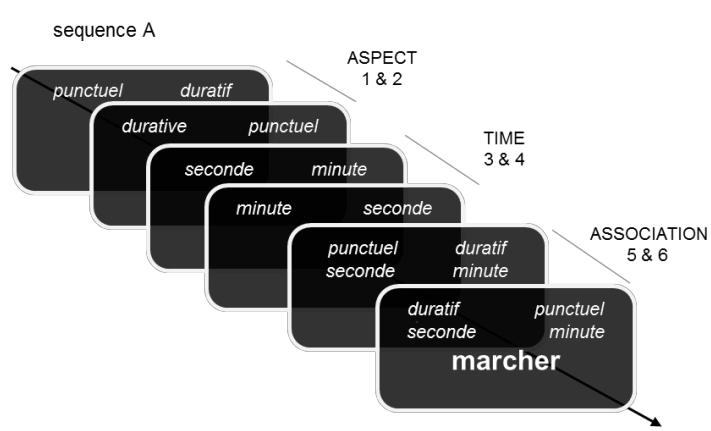

C

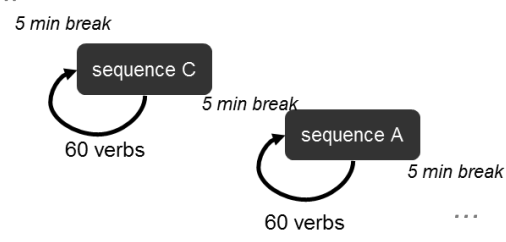

B

\begin{tabular}{|c|c|c|c|c|c|c|c|}
\hline & & \multicolumn{6}{|c|}{6 sequences of categorization } \\
\hline \multicolumn{2}{|c|}{ CATEGORIZATION } & A & B & C & D & E & $\mathbf{F}$ \\
\hline \multirow{2}{*}{ ASPECTUAL } & Test 1 & punctual | durative & punctual | durative & punctual | durative & punctual | durative & punctual | durative & punctual | durative \\
\hline & Test 2 & durative | punctual & durative | punctual & durative | punctual & durative | punctual & durative | punctual & durative | punctual \\
\hline \multirow{2}{*}{ TEMPORAL } & Test 3 & second | minute & minute | hour & hour | day & second | hour & second | day & minute| day \\
\hline & Test 4 & minute | second & hour | minute & day | hour & hour |second & day | second & day | minute \\
\hline ASSOCIATION & Test 5 & $\begin{array}{c}\text { second | minute } \\
\text { punctual | durative }\end{array}$ & $\begin{array}{c}\text { minute | hour } \\
\text { punctual | durative }\end{array}$ & $\begin{array}{c}\text { hour | day } \\
\text { punctual | durative }\end{array}$ & $\begin{array}{c}\text { second | hour } \\
\text { punctual | durative }\end{array}$ & $\begin{array}{c}\text { second | day } \\
\text { punctual | durative }\end{array}$ & $\begin{array}{c}\text { minute| day } \\
\text { punctual | durative }\end{array}$ \\
\hline
\end{tabular}

Figure 1: Experimental Paradigm. A: One sequence consisted in a series of 6 categorization tests. The illustrated verb marcher (to walk) had to be classified as being punctual or durative (Aspectual Tests 1 and 2), then as belonging to the second or minute timeframe (Time Tests 3 and 4), and last, as one of the four possible combinations of aspect and timeframe (Association Tests 5 and 6). The tests were repeated to counter-balance the left/right categories and assess a possible interaction with response mapping (see Mental Time Line hypothesis). B: Six possible sequences (A to B) assessed the pairings of the four possible timeframes per verb. C: Sequences were shuffled. All sixty verbs were sequentially tested within a sequence, with the order of verb presentation shuffled within each sequence.

The task comprised a sequence of six consecutive categorization tests (Figure 1A). Sequences were ran by block so that all sixty verbs would be tested with the sequence in a row (Figure 1B). In each possible sequence (Figure 1C; sequences A to F), tests 1 and 2 were aspectual categorizations titrating whether participants preferred to classify a verb as punctual or as durative. Aspectual categorization was then followed by the time categorization tests ( 3 and 4), which titrated whether a verb was systematically associated with possible time scales. Four time scales were tested, which included 'second', 'minute', 'hour' and 'day'. All possible combinations of time scales were tested yielding six possible pairings: second $\mid$ minute; second | hour; second | day; minute | hour; minute | day and hour | day. Each time scale was tested three times out of the six possible sequences of time categorizations (Figure 1C). In categorization tests 1 to 4 , each category was tested twice, either when presented on the left or on the right of the screen. This was done to control for possible cultural spatial associations notably mental time line (Bonato et al, 2012; Furhman \& Boroditsky, 2010). The association categorization tested the existence of an implicit association between aspect categories and duration categories (tests 5 and 6). 
The sequence order was pseudo-randomized across participants. Each of the sixty possible verbs, independently of its a priori aspectual property, was tested six times through each of the six possible sequence (A to F). Each verb was thus presented for a total of 36 times ( 6 sequences * 6 presentations). This yielded a total of 72 trials for the aspectual categorization (2 tests $(1: 2)$

* 6 sequences $\left.(\mathrm{A}: \mathrm{F})^{*} 6\right)$; a total of 36 trials for each time category irrespective of its pairings (2 tests $(3: 4) * 3$ sequences * 6); and a total of 18 trials for each aspectual $\mathrm{x}$ time categories as a priori congruent (test 5 ) or incongruent (test 6$)(1$ test $* 3$ sequences $* 6$ ).

Participants were given 5 to 10 minutes break after they completed a sequence of 60 verbs and could take a break whenever they wished to (e.g., Figure 1B). Each experimental session lasted an average 1.5 hours.

\section{Statistical Analysis}

All statistical analyses were performed using $\mathrm{R}$ (version 3.2.4; R Core Team) and RStudio environment (RStudioTeam 2015) with the lme4, betareg and lsmean software packages. In this modified IAT, we did not assess error rates as there was no truth value regarding the categories that we tested. The first four categorization tests (1:4) aimed at providing a characterization of whether participants would readily and systematically classify words as a function of aspect and time scale. For this assessment, we thus report thorough descriptive statistics but also provide descriptions of how results conformed with the overt initial classification of verb selection. The means and the standard deviations were used to describe participant's response times (RT). To verify the factors that influenced the RTs, log-linear regression models with gamma distributions and random effects (McCulloch et al. 2001) were used both for participants and for verbs. The fact that the same participant and the same verb were measured more than once generated a grouping structure that had to be properly addressed since it violated the basic assumption of independence of observations. In the presence of pooled data, we assumed that there was a correlation between the observations of the same individual and the verb, but that there was no correlation between the observations of participants and different verbs. One way to account for the correlation between repeated measures of the same individuals was to use mixed effect models (Fitzmaurice, Laird and Ware, 2012).

The RTs showed asymmetric distributions to the right, which made it impossible to adjust any method that used the Normality assumption. To identify possible atypical intra-subject values in the database, the outlier labeling rule (Hoaglin, Iglewitz, Turkey, 1986) was used with g=2.2. Overall, 1987 (7.66\%) atypical RTs observations were found according to the Outlier Labeling Rule. In the analysis by participant, participant 9 presented the highest number of atypical 
observations $(206 ; 9.53 \%)$ and participant 6 , the lowest number of atypical observations (77; $3.56 \%$ ). Although discrepant observations were found, we decided not to eliminate them from the analyses, since the model applied to measure influence factors on the RTs was able to absorb the asymmetric distribution behavior and the variability structure of the data.

In order to assess the grouping of verbs, we used the cluster analysis via Fuzzy Logic (Bezdek, 1981). The cluster analysis aims to form groups that are internally homogeneous and heterogeneous. Fuzzy cmeans (FCM) is a grouping method that allows one part of the data to belong to two or more clusters. For this, the method estimates the degree of fuzzification of each of the elements in relation to the available clusters. Elements that have similar degrees of relevance for two or more groups are interface (or border) elements. To define the optimal number of groups, the Silhouette method was used (Rousseeuw, 1987). In summary, the average silhouette approach measures the quality of a grouping by determining how well each object stands within its cluster. A high average width of the silhouette indicates a good grouping. To evaluate the differences between the characterizations of the groups formed, we used the Mann-Whitney test (Hollander and Wolfe, 1999). To evaluate the agreement between the classifications, we used the Coefficient of Kappa (Cohen, 1968) which we interpreted with the Landis and Koch scale (1977).

\section{Results}

\section{Robust aspectual categorization of verbs as punctual or durative}

First, we asked whether the 60 selected verbs (Table 1) would systematically be classified as being punctual or durative and thus tested whether participants reliably classified each verb according to one of these two aspectual categories. Figure $\mathbf{2 A}$ reports that over all six possible series (A-F) in tests 1 and 2, slightly more verbs were classified as being punctual than durative (54\% and $53.7 \%$, respectively). The partitioning of the verbs matched the initial explicit classification provided by the three independent participants: most of the initially classified punctual verbs (85.69\% and $85.79 \%)$ and durative verbs $(77.18 \%$ and $78.06 \%)$ were classified accordingly in both aspectual categorization tests 1 and 2. Table 1 in the Supplemental Material available online shows the descriptive analysis of the aspectual categorization outcomes. On the basis of participants' categorical responses, and consistent with a majority of punctual ratings, 2 out of 60 verbs seemed to differ from the initial aspectual category they were defined by (Fig. 2A and Table 1: raser (to shave) and fumer (to smoke) were classified as being more punctual than durative). 
The speed with which participants classified verbs can be taken as an indicator of the strength of the association with a category (Greenwald et al., 1998). Hence, reaction times (RTs) were of particular interest. Fig. 2A (right panel) shows the distribution of RTs per verb in the first and second aspectual categorization tests (dark and light grey, respectively). The first striking feature was that RTs did not appear maximal for verbs that were most difficult to categorize (i.e., one's expectation that verbs closer to the $50 \%$ would take longer to classify was not observed). Rather, RTs seemed to vary orthogonally to the likelihood of category belongingness (Fig. 2A, right panels). The median RTs for verbs classified as punctual were faster than for verbs classified as durative (test $1: 0.81 \mathrm{~s}$ and $0.87 \mathrm{~s}$, respectively; test 2: $0.86 \mathrm{~s}$ and $0.92 \mathrm{~s}$, respectively). Interestingly, participants were faster when their classification conformed with the $a$ priori aspectual categorization of the verb for both durative and punctual (test 1), and participants were systematically faster in test 2 than in test 1, irrespective of classification scores (Table 2 in the Supplemental Material available online). Fig 1 in the Supplemental Material available online depict random effects of verbs and participants.

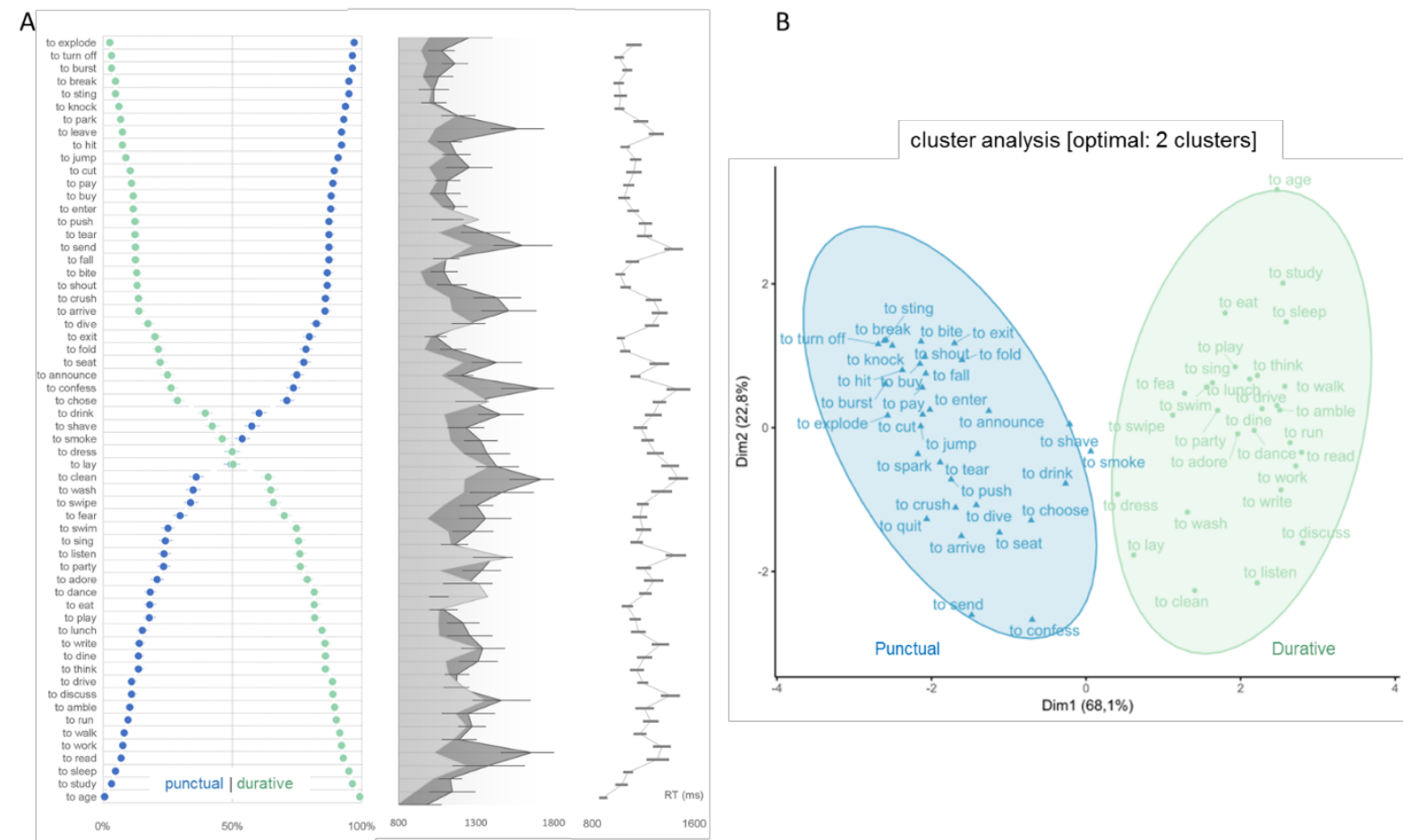

Figure 2: Aspectual categorization. Panel A: Aspectual classification of verbs as punctual (green) or durative (blue) in tests 1 and 2. Reaction Times (RTs) in test 1 (dark grey) were slower than in test 2 (light grey). RTs combined in both aspectual categorization tests (rightest panel) showed no increase at the boundary. Bars are 2 s.e.m. Panel B: Outcome of the Fuzzy cmeans cluster analysis explaining $90.9 \%$ of the variance. Overall, speeded classification of verbs matched well with their overt classification (Table 1).

To get a robust statistical assessment of how participants classified verbs, we used participants' full categorization data and RTs in a Fuzzy cmeans cluster analysis, which optimally assessed 
the similarity of each verb, and allowed verbs to belong to several clusters. This method confirmed that the optimal number of clusters to explain aspectual categorization was two (Fig. 2B) and only two verbs belong to the two clusters: habiller (to dress) and fumer (to smoke). The percentage of punctual and durative in both tests 1 and 2 significantly differed between the two clusters ( $p=0.000$; Table 3 in the Supplemental Material available online) and a significant difference of mean RTs was found between the two clusters only in Test 2. Otherwise, the analysis presented a good fit and accounted for $90.9 \%$ of variance in the data. The full outcome of the clustering computations is provided in Table 4 in the Supplemental Material available online.

\section{Punctual verbs were easier to classify than durative verbs}

In a series of reading experiments and sensicality judgements, Coll-Florit \& Gennari (2011) reported two important observations. First, participants consistently judged punctual events (e.g. to recognize an old friend) faster than durative states (e.g. to appreciate an old friend). Second, participants read sentences more quickly when verbs were inflected in perfect tenses (punctual contexts; e.g. the doorman covered the sign) than in imperfect tenses (durative contexts; e.g. the doorman was covering the sign), especially when sentences were presented in the absence of discourse contexts. The authors proposed that the participants' pattern of RTs reflected that punctual events had an easier mental representation than durative events. Here, participants also answered faster when verbs were classified as punctual than when they were classified as durative (tests 1: $0.81 \mathrm{~s}$ and $0.87 \mathrm{~s}$, respectively; test $2: 0.86 \mathrm{~s}$ and $0.92 \mathrm{~s}$ respectively). Using a speeded aspectual categorization in absence of any contextual cues, we thus corroborate prior observations (Coll-Florit \& Gennari, 2011).

\section{Robust categorization of verbs as a function of timeframes}

For the categorization of verbs as a function of timeframes (categorization tests 3 and 4; Fig. 1B), a given duration category appeared in three sequences out of the six possible sequences. For instance, the category 'second' was paired with minute, hour and day, while the other three pairs of categories were minute $\mid$ hour, minute $\mid$ day, and hour $\mid$ day. Fig. 3 depicts the relative percentages of temporal categorization considering that each time scale appeared half of the times a verb had to be classified (i.e., in 3 out of the 6 possible sequences; Fig. 1C). A descriptive analysis of the data is provided in Table $\mathbf{5}$ in the Supplemental Material available online: the reported percentage was relative to the three tests in which participants could 
actually select a given timeframe. For instance, the verb asseoir (to sit) was classified as belonging to the category 'second' $77.78 \%$ of the times when this category was available, and $13.89 \%$ of the time as 'day' when this category was available. Overall, participants categorized most verbs as belonging to the minute category in both temporal categorization tests $3(32.87 \%)$ and $4(32.34 \%)$.

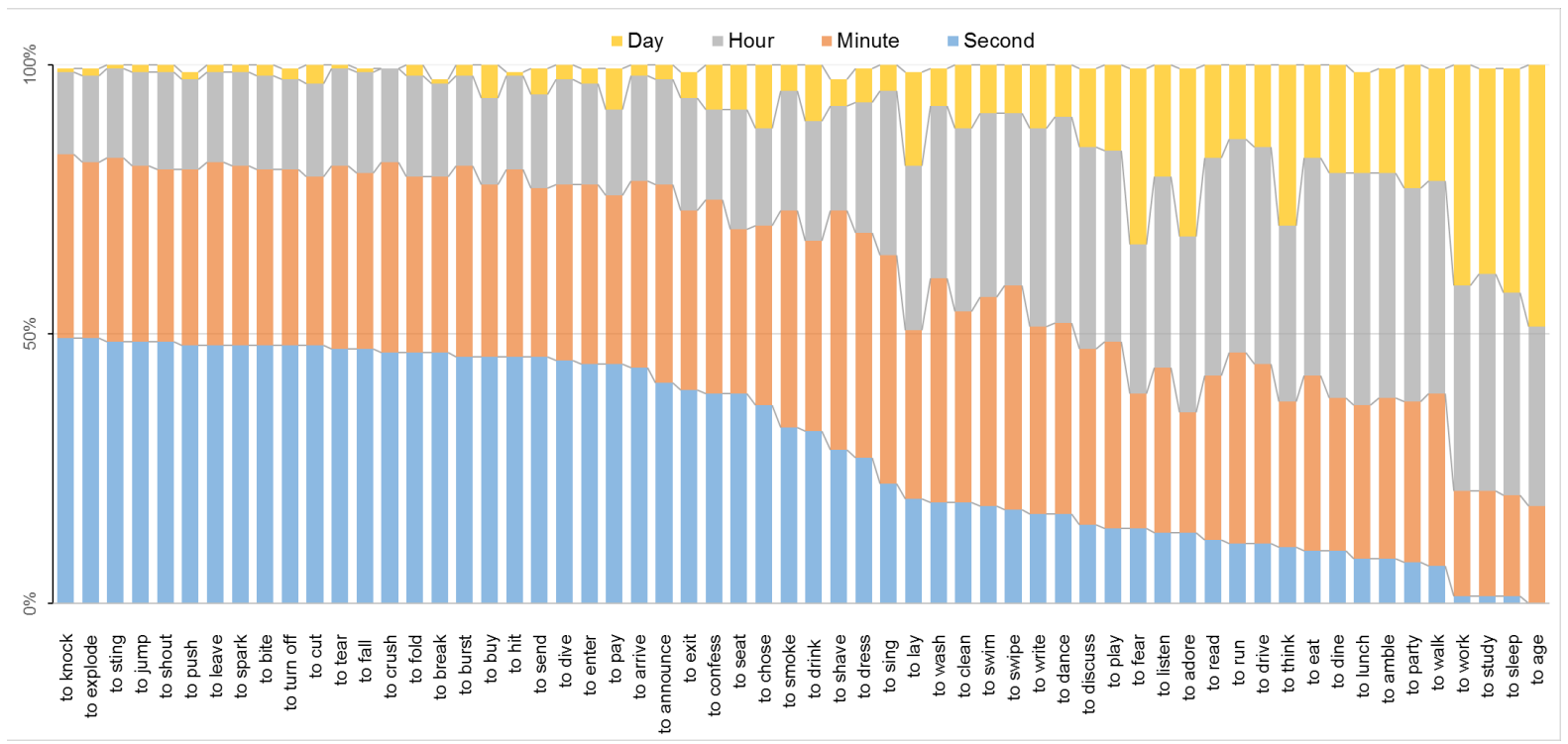

Figure 3: Temporal categorization. Descriptive temporal classification of verbs as second (blue), minute (orange), hour (gray) or day (yellow) in tests 3 and 4.

Pulling the data as a function of the percentage of time participants selected the shortest category of the presented pair, irrespective of pairings, provided a synthetic illustration (Fig. 4A) of the systematicity with which each verb was classified in the temporal categorization tests, given the possible category pairing. Similar to the RT pattern observed in aspectual categorization, RTs did not clearly increase at the boundary (Fig. 4A, right panel). In both temporal categorizations, RTs for day were significantly longer than for second and in test 3 , RTs for day and hour responses were significantly longer than for second (Table 6 in the Supplemental Material available online). Overall, the following verbs showed significantly longer RTs than all other verbs: écouter, discuter, chanter, laver, avouer, dancer and penser (to listen, to discuss, to sing, to wash, to confess, to dance, and to think). On the contrary, the following verbs showed significantly shorter RTs as compared to all other verbs: mordre, acheter, piquer, and vieillir (to bite, to buy, to sting and to age). Random effects are provided in Fig. 2 in the Supplemental Material available online.

As for aspectual categorization, we performed a cluster analysis by considering participants' temporal categorizations and RTs. The Silhouette method suggested that the optimal number of clusters explaining temporal categorization data was two (Fig. 4B). Importantly, we found 
that the percentage of second, minute, day and hour responses significantly differed between the two clusters ( $p=0.000$; Table 7 in the Supplemental Material available online) as well as the mean RTs, with faster RTs for the shorter classification. The cluster analysis via Fuzzy cmeans (Table 8 in the Supplemental Material available online) suggested three verbs at the border of the clusters: avouer (to confess; membership degrees of. 48 and 0.52), vieillir (to age; membership degrees of 0.45 and 0.55 ) and balayer (to sweep; membership degrees of 0.48 and 0.52 ). The two-dimensional cluster could explain $82.8 \%$ of the variance in the data.

Importantly, that two clusters were better suited to fit the data was not surprising given the current design constraining participants to categorize each verb according to two of the possible four categories in a given trial, and fifty percent of the time, the likeliest category may not have been available (i.e. 2-AFC and not 4-AFC). For illustration, we also provide in Fig. 3 in the Supplemental Material available online a four-cluster analysis obtained in the temporal categorization, with a large cluster overlap due to the forced pairings and choices; in spite of its inadequacy to account for the full set of data, the clustering is not fully random and rather coherent with the optimal two clusters grouping reported in Fig 4.

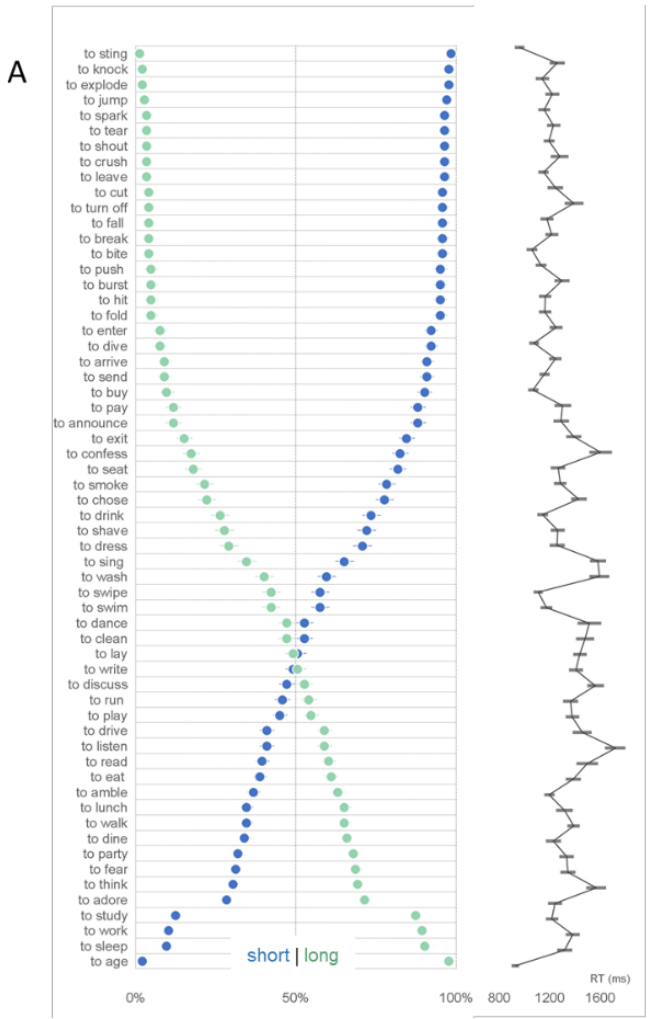

\section{B}

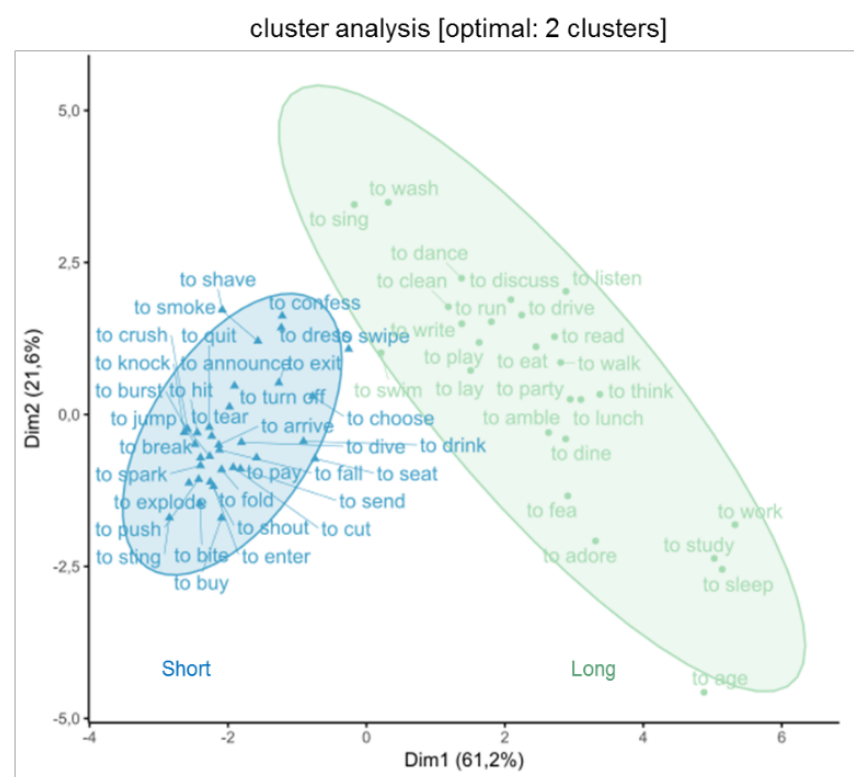

Figure 4: Temporal categorization. Panel A: Temporal classification of verbs as the shortest or the longest in the pair (blue or green, respectively) in tests 3 and 4. RTs showed no increase at the boundary. Bars are 2 s.e.m. Panel B: Outcome of the cluster analysis explaining $82.8 \%$ of the variance. 


\section{Implicit association between aspectual categorization and timeframes}

When sorting RTs in each temporal category as a function of the aspectual categorization of verbs obtained in test 1 and 2, a clear trend emerged so that participants were fastest to classify punctual verbs when temporal categories were shortest, and fastest to classify durative verbs when the temporal categories were longest (Fig. 5A). Table 2 shows the cross-tabulation of individuals in aspectual categorization (tests $1 \&$ 2) given the responses in temporal categorization (tests $3 \& 4$ ). Most verbs classified as second $(80.63 \%)$ and minute $(55.79 \%)$ were also classified as punctual; most verbs classified as hour (60.68\%) and day (85.85\%) in temporal categorization tests were also classified as durative during aspectual categorization. This provided a first general indicator of a likely correspondence between linguistic aspect and psychological timeframe.

\begin{tabular}{lcc|cc}
\hline & \multicolumn{2}{c|}{ Punctual } & \multicolumn{2}{c}{ Durative } \\
\cline { 2 - 5 } & $\mathbf{N}$ & $\mathbf{\%}$ & $\mathbf{N}$ & $\mathbf{\%}$ \\
\hline Second & 2032 & $\mathbf{8 0 , 6 3 \%}$ & 488 & $19,37 \%$ \\
Minute & 1565 & $\mathbf{5 5 , 7 9 \%}$ & 1240 & $44,21 \%$ \\
Hour & 896 & $39,32 \%$ & 1383 & $\mathbf{6 0 , 6 8 \%}$ \\
Day & 137 & $14,15 \%$ & 831 & $\mathbf{8 5 , 8 5 \%}$ \\
\hline \hline
\end{tabular}

Table 2: Aspectual categorization (tests 1 and 2) given participants' temporal categorization (tests 5 and 6).

In test 5 (Table 9 in the Supplemental Material available online), most verbs (61.64\%) were classified as punctual \& shorter with the punctual \& second association being the most frequently selected (27.35\%). In test 6 (Table 10 in the Supplemental Material available online), participants classified in a balanced manner punctual \& longer in the pair $(51.19 \%)$ and durative \& shorter in the pair (48.81\%). The most frequently selected categories were punctual \& second (25.95\%) and durative \& day (25.86\%). In test 5, most punctual verbs (88.98\%) were classified as shorter \& punctual and most of durative verbs $(65.88 \%)$ were classified as longer \& durative. Additionally, responses to longer $\&$ durative were on average $21 \%$ slower than shorter \& punctual $(\mathrm{p}<0.005)$. In test 6 , most punctual verbs $(51.57 \%)$ were classified as longer + punctual while many durative verbs $(49.63 \%)$ were classified as longer + punctual. No significant differences in RTs were observed in test 6 .

Critically, we assessed the statistical agreement between the clusters obtained in aspectual and temporal categorizations. A Kappa coefficient of 0.93 (Fig. 5C) revealed that most verbs classified as punctual were indeed associated with the shortest timeframe of each pair $(96.9 \%)$ whereas a great majority of verbs classified as durative were associated with the 
longer timeframe of each pair (96.4\%). Only two verbs did not conform to this: avouer (to confess; rated punctual with longer timeframes) and habiller (to dress; rated durative with shorter timeframes). These results indicated that the linguistic aspect of verbs generally agreed with the psychological classification of the timeframe of the action.

A

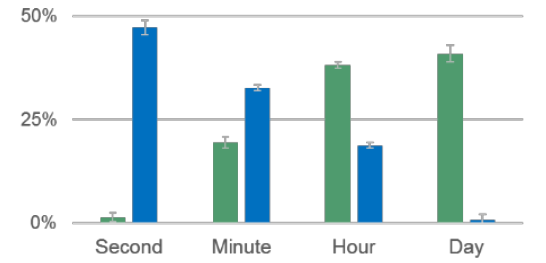

B

Kappa $=0.933(z=7.24, p=4.44 e-13)$

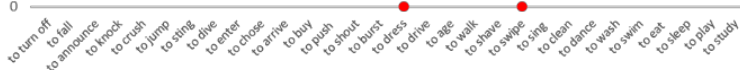

$\mathrm{E}$

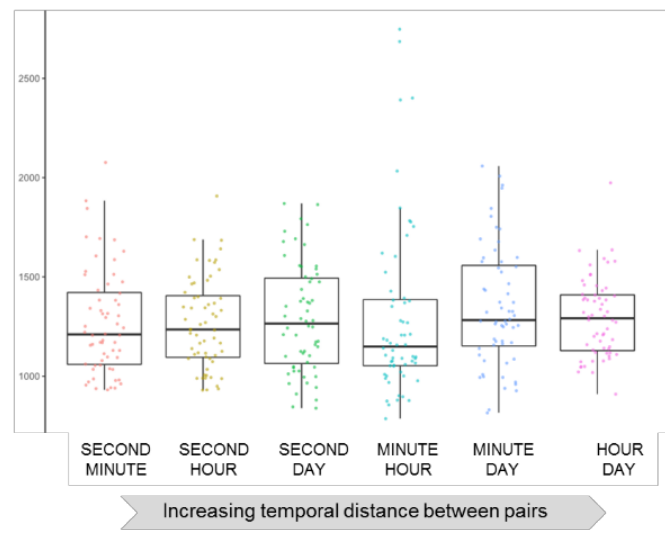

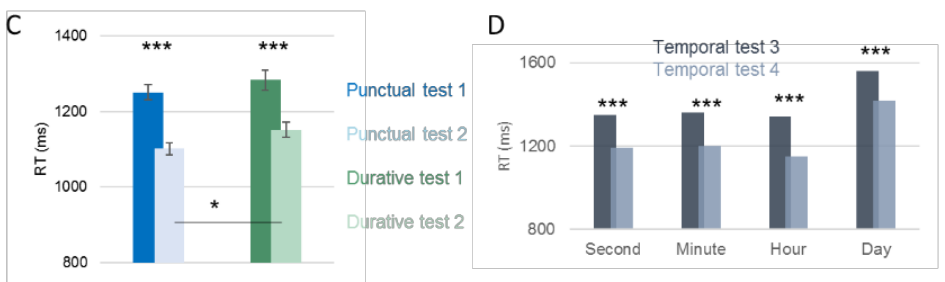

Figure 5: The congruence between linguistic aspect and psychological timeframe of verb meaning shows no evidence for a mental time line or symbolic distances. A: The punctual (blue) and durative (green) categories obtained in test 1 and 2 were generally congruent with the shortest to longest timeframes of tests 3 and 4, respectively. Bars are 2 s.e.m. B: Outcome of cluster agreement analysis highlighting in red the two exceptions (see Text). C and D: RTs in tests 1 and 3, in which the placement of categories was spatially congruent with the mental time line hypothesis (punctual/shortest on the left; durative/longest on the right) showed significantly longer RTs than in tests 2 and 4, in which the placement of categories was incongruent with the mental time line hypothesis. E: We found no evidence for a dependency of RTs as a function of temporal distances between timeframes.

\section{No evidence for a spatialized mental time line of aspect or timeframe during semantic categorization}

According to the mental time line hypothesis (MTL; Bonato et al, 2012), culture and writing direction may define how humans spatialize time overtly: as applied to the French culture tested here, punctual events and shorter timeframes should be associated with the left side, whereas durative events and longer timeframes should be associated with the right side (Bonato et al, 2012; Furhman \& Boroditsky, 2010). In our study, aspectual and temporal categories were displayed on the left and right side of the screen. Hence, to control for a possible spatial bias, aspectual and temporal categorizations were tested twice to counterbalance the presentation side of each category. This design allowed testing the prediction of a spatialized representation for time, both with respect to linguistic aspect and to psychological temporal categorizations. 
Following the MTL hypothesis, the first categorization test in both the aspectual (test 1) and the temporal (test 3) categorizations were spatially congruent with the MTL, whereas the second categorization test (tests 2 and 4 for aspectual and temporal categorization, respectively) were spatially incongruent with it. The main experimental prediction was thus that RTs should be faster in tests 1 than in test 2, and faster in tests 3 than in test 4 .

This is not what we observed (Figure 5C-D). First, we found a significant difference in RTs between test 1 and 2 for both punctual and durative responses $(p=0.000)$ : given the same participants and the same verbs, the mean RTs in test 2 was $10 \%(+/-4 \%)$ faster than in test 1 for punctual classifications, and 20\% (+/-7\%) faster than in test 1 for durative responses. RTs significantly decreased in test 2 as compared to test 1 for all verbs (punctual: $\beta=-0.13+/$ $0.02, p=0.000$; durative: $\beta=-0.08+/-0.02, p<0.001)$. Thus, the directionality of the effects went opposite to the MTL predictions in aspectual classifications. The same analysis carried out on the temporal categorizations (tests 3 and 4) went in the opposite direction of the MTL predictions: participants were faster in test 4 as compared to test 3 for all verbs and timeframes (second: $\beta=-0.10+/-0.0, p=0.000$; minute: $\beta=-0.11+/-0.01, p=0.000$; minute: $\beta=-0.13$ $+/-0.01, \mathrm{p}=0.000$; minute: $\beta=-0.10+/-0.01, \mathrm{p}=0.000)$.

A possible confound for the lack of evidence supporting the MTL hypothesis would be a general fastening of RTs over time due to participants becoming more familiar with the task requirements. Such decrease of RT would explain why participants were systematically faster in tests 2 and 4 as compared to tests 1 and 3. To evaluate the possible confound of a faster RTs trend in the course of the successive classification tests, we used an lme model for RTs using the order of tests as an explanatory variable. We found a significant sequential effect of testing ( $\beta=0.07, p=0.000)$ in relation to RTs but the trend was towards an increase of RTs by $7 \%$ $(+/-1 \%)$, not a decrease. Hence, the significant differences in RTs across tests could not be accounted for a global decrease in RTs in the course of the experiment. If anything, this RTs trend would have favored the MTL hypothesis. We thus found not robust evidence supporting a MTL for the semantic temporal associations of verb meaning in line with controversial results of linguistic relativity for the representation of time (January \& Kako, 2007; Tse \& Altarriba, 2008).

Consistent with this, we also did not find supporting evidence for symbolic distance effects in the temporal categorization task. Specifically, symbolic distance effects would predict that classifying verbs between timeframes that are far apart should be faster than for classifying verbs that are closer in timeframes (e.g. Moyer \& Boyer, 1976; Gauthier \& van Wassenhove, 2016): for instance, the temporal classifications of verbs given the choice (second $\mid$ day) should be faster than for the choice (second $\mid$ minute). However, we found no significant effects of 
temporal distance on RTs (Figure 5E: $\mathrm{F}(5,354)=0.579, \mathrm{p}=0.716)$ suggesting that the temporal distance between pairs of timeframes did not contribute to the variance in RTs. Hence, we found no robust or systematic evidence in support of the MTL regarding the representation of implicit timing conveyed by verb meaning. The current task design seems to capture the semantics of time, not the magnitudes of time.

\section{Discussion}

Our study shows that, even in the absence of contextual cues, speakers of a language (here, French) systematically agreed on the judgement of aspectual categories so that verbs were robustly associated with punctual or durative categories using a speeded classification task. Our results suggest that verbal aspect bears a psychological reality, which is shared by members of the same language. Additionally, our results for aspectual categorization agree with, and build on, previous observations (Coll-Florit \& Gennari, 2011) in that durative events have a higher processing cost than punctual ones. Second, our results show a robust agreement among participants regarding the temporal categorization of verbs. Although the temporal categories were split given four fuzzy options, the classification remained extremely robust. Last, and crucially, we showed that aspectual categorization closely matched temporal categorizations so that durative verbs were robustly associated with longer timeframes, whereas punctual verbs were readily associated with shorter timeframes. From these set of results, we conclude that linguistic relativity implicitly captures the psychological reality of subjective time. In this design, we did not find evidence supporting the predictions of a Mental Time Line hypothesis. We suggest that this experimental approach enables to capture the semantics of time conveyed by language (e.g. Evans, 2003), as opposed to the perceptual magnitudes or perceptual durations, most readily studied in the context of a Mental Time Line (e.g. Bonato et al, 2012).

Overall, our study suggests that words, outside of a sentential context, may implicitly convey the temporal framing or implicit timing of events with one's interlocutor. There are several limitations and possible extensions of this work. Notably approaching the issue from a multicultural perspective (linguistic relativity) and extending such testing to other languages would help better understand the linguistic relations between words and psychological time. Additional work will be pursued in this direction to explore how this relation may have consequences on sentence processing, and specifically focus on aspectual coercion, thereby 
approaching the influence of contextual cues in the semantic representation of linguistic events. Crucially, the systematic categorization of verbs as a function of aspect and timeframes suggest that the semantics conveyed by linguistic events bear a psychological reality even in the realm of experiential temporality. This study provides a proof of concept for a quantified approach of the semantics of time. We hope in the near future to extend this approach and contribute to a better understanding between the psychology of event timing, and the linguistic representation of time across cultures.

\section{Author Contributions}

TOMdS and VvW designed the study. TOMdS acquired the data. TOMdS and VvW analyzed the data, interpreted the results, and wrote the MS.

\section{Acknowledgments}

We thank member of the Cognition \& Brain Dynamics lab, Nina Kazanina and Silvia Gennari for their comments on a preliminary version of the article.

\section{Declaration of Conflict of interests}

The authors declare no conflict of interest.

\section{Funding}

This work was conducted thanks to a SANDWICH fellowship attributed to TOMdS (CapesBEX-10.265-12-0) and an ERC-StG-263584 to VvW. 


\section{References}

1. Bezdek, J.C. (1981). Pattern Recognition with Fuzzy Objective Function Algorithms. Plenum. New York.

2. Block, R. A. (1990) Cognitive models of psychological time. New Jersey, Erlbaum, Hillsdale.

3. Bonato, M., Zorzi, M., \& Umiltà, C. (2012). When time is space: evidence for a mental time line. Neuroscience \& Biobehavioral Reviews, 36(10), 2257-2273.

4. Coll-Florit, M. \& Gennari, S. (2011) Time in language: Event duration in language comprehension. Proceedings of the CUNY human sentence processing conference

5. De Swart, H. (1998) Aspect shift and coercion. Natural Language \& linguistic Theory, n. 16, 347385.

6. Evans, V. (Ed.). (2003). The structure of time: Language, meaning and temporal cognition. John Benjamins Publishing.

7. Evans, V. (2004). 22 How we conceptualise time: language, meaning and temporal cognition.

8. Fitzmaurice, G. M., Laird, N. M., Ware, J. H. (2012) Applied longitudinal analysis. John Wiley \& Sons.

9. Fuhrman, O., \& Boroditsky, L. (2010). Cross-cultural differences in mental representations of time: Evidence from an implicit nonlinguistic task. Cognitive Science, 34(8), 1430-1451.

10. Gauthier, B., \& van Wassenhove, V. (2016). Cognitive mapping in mental time travel and mental space navigation. Cognition, 154, 55-68.

11. Greenwald, A. G., McGhee, D. E., \& Schwartz, J. L. (1998). Measuring individual differences in implicit cognition: the implicit association test. Journal of personality and social psychology, 74(6), 1464.

12. Greenwald, A. G., Nosek, B. A., \& Banaji, M. R. (2003). Understanding and using the implicit association test: I. An improved scoring algorithm. Journal of personality and social psychology, 85(2), 197.

13. Hoaglin, D., Iglewicz, B., and Tukey, J. (1986) Performance of some resistant rules for outlier labeling, Journal of American Statistical Association, 81, 991-999.

14. Jackendoff, R. (1997) The architecture of the language faculty. Cambridge, MA: MIT Press.

15. January, D., \& Kako, E. (2007). Re-evaluating evidence for linguistic relativity: Reply to Boroditsky (2001). Cognition, 104(2), 417-426.

16. Kay, P. \& Kempton, W. (1984). What is the Sapir-Whorf hypothesis American Anthropologist, 86, 65-79

17. Kleiner, M., Brainard, D., Pelli, D. (2007) What's new in Psychtoolbox-3? Perception, 36, ECVP, 2007

18. Knott, A. (2012) Sensorimotor cognition and natural language syntax, Cambridge, MA: The MIT Press.

19. McCulloch, C. E.; Neuhaus, J. M. (2001) Generalized linear mixed models. John Wiley \& Sons, Ltd. 
20. Moyer, R. S., \& Bayer, R. H. (1976). Mental comparison and the symbolic distance effect. Cognitive Psychology, 8(2), 228-246.

21. New B., Pallier C., Ferrand L., Matos R. (2001) Une base de données lexicales du français contemporain sur internet: LEXIQUE, L'Année Psychologique, 101, 447-462, $<$ http://www.lexique.org $>$

22. New, B., Pallier, C., Brysbaert, M., Ferrand, L. (2004) Lexique 2: A New French Lexical Database. Behavior Research Methods, Instruments, \& Computers, 36 (3), 516-524

23. Nguyen, E.T. (2012) A Linguistic Relativity Study Involving the Visual Mismatch Negativity Component and English and Vietnamese Colors, A Thesis Presented to The Division of Philosophy, Religion, Psychology, and Linguistics of the Reed College.

24. Pullum, G. (1991) The Great Eskimo Vocabulary Hoax and Other Irreverent Essays on the Study of Language. University of Chicago Press.

25. Rosen, S. T. (1999) The Syntactic Representation of Linguistic Events, GLOT International 4(2): 3- 11.

26. Rousseeuw, P.J. (1987) Silhouettes: A graphical aid to the interpretation and validation of cluster analysis. J. Comput. Appl. Math., 20, 53-65.

27. Tenny, C.L. (1992) The Aspectual Interface Hypothesis. In: SAG, Ivan A. ; SZABOLCSI, Anna (eds.) Lexical Matters, 1-28. Stanford: Center for the Study of Language and Information.

28. Tse, C. S., \& Altarriba, J. (2008). Evidence against linguistic relativity in Chinese and English: A case study of spatial and temporal metaphors. Journal of Cognition and Culture, 8(3), 335-357.

29. Ullrich, J. (2008) New Lakota Dictionary. Lakota Language Consortium. 


\section{Figure Legends}

Figure 1: Experimental Paradigm. A: One sequence consisted in a series of 6 categorization tests. The illustrated verb marcher (to walk) had to be classified as being punctual or durative (Aspect tests 1 and 2), then as belonging to the second or minute timeframe (Time tests 3 and 4), and last as one of the four possible combinations of aspect and timeframe (Association tests 5 and 6). The tests were repeated to counter-balanced the left/right categories and test the Mental Time Line hypothesis. B: Six possible sequences (A to B) assessed the pairings of the four possible timeframes per verb. C: Sequences were shuffled. One a sequence started, all sixty verbs were sequentially tested in this sequence. The order of verb presentation was shuffled within each sequence.

Figure 2: Aspectual categorization. Panel A: Aspectual classification of verbs as punctual (green) or durative (blue) in tests 1 and 2. Reaction Times (RTs) in test 1 (dark grey) were slower than in test 2 (light grey). RTs combined in both aspectual categorization tests (rightest panel) showed no increase at the boundary. Bars are 2 s.e.m. Panel B: Outcome of cluster analysis explaining $90.9 \%$ of the variance. Overall, speeded classification of verbs matched well with their overt classification (Table 1).

Figure 3: Temporal categorization. Descriptive temporal classification of verbs as second (blue), minute (orange), hour (gray) or day (yellow) in tests 3 and 4.

Figure 4: Temporal categorization. Panel A: Temporal classification of verbs as the shortest or the longest in the pair (blue or green, respectively) in tests 3 and 4. RTs showed no increase at the boundary. Bars are 2 s.e.m. Panel B: Outcome of the cluster analysis explaining $82.8 \%$ of the variance.

Figure 5: The congruence between linguistic aspect and psychological timeframe shows no evidence for a mental time line or symbolic distances. A: The punctual (blue) and durative (green) categories obtained (test 1 and 2) are generally congruent with shortest to longest timeframes (tests 3 and 4), respectively. Bars are 2 s.e.m. B: Outcome of cluster agreement analysis. C and D: RTs in tests 1 and 3 (congruent with placement of categories with a mental time line) showed significantly longer RTs than in tests 2 and 4, in which the placement of categories was incongruent with a mental time line. E: no evidence for a dependency of RTs as a function of temporal distances between timeframes. 


\section{Supplemental Material available online}

\section{SUPP. FIGURE 1}
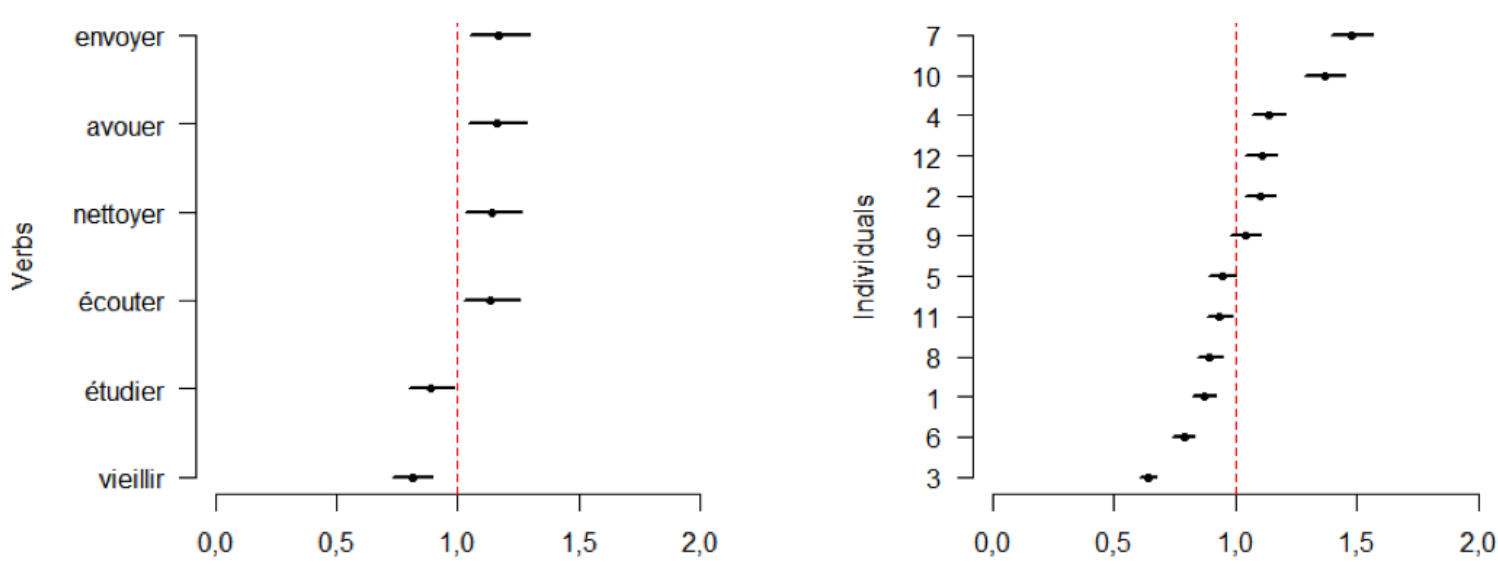

Supp. Figure 1: Random effects of verbs and participants in aspectual categorization (tests 1 and 2). Left panel: The verbs envoyer, avouer, nettoyer and écouter showed significantly longer RTs than the mean result of all verbs. The verbs étudier and vieillir showed significantly shorter RTs than the mean result of all verbs. Right panel: random effect of participants on RTs.

\section{SUPP. FIGURE 2}
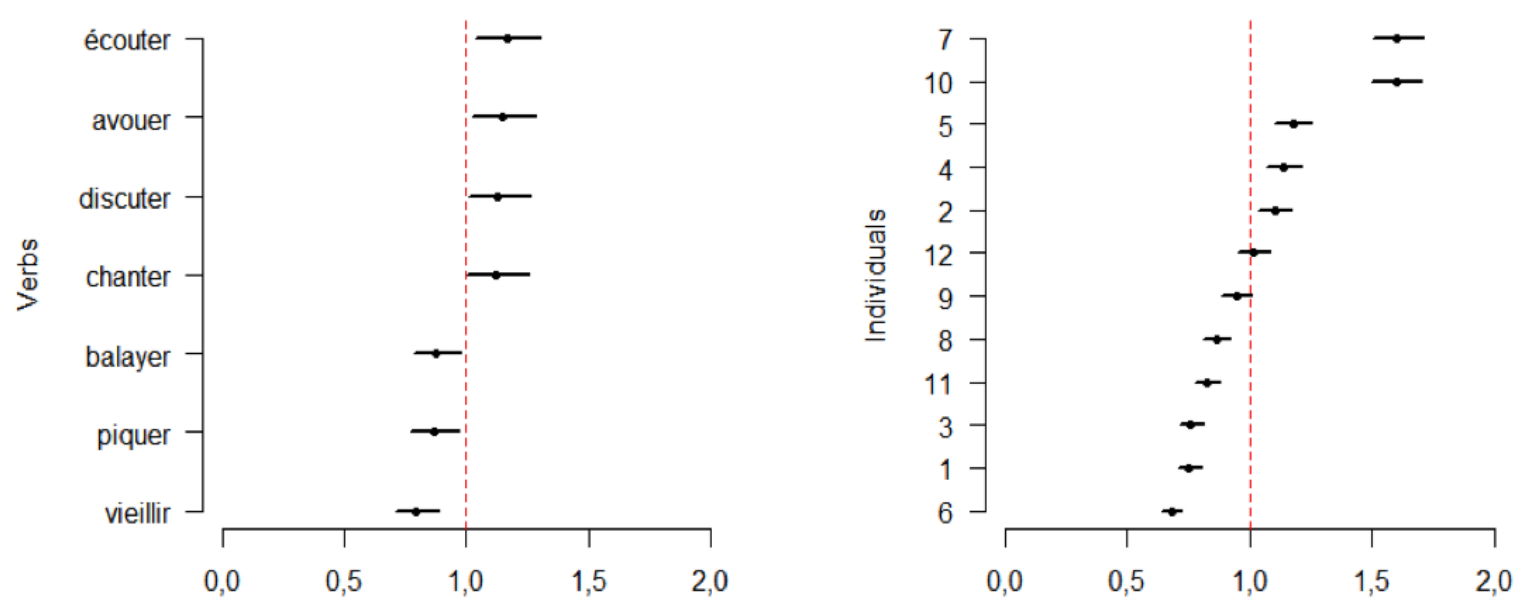

Supp. Figure 2: Random Effects of the verb and participants in temporal categorization (tests 3 and 4) . Left panel: The verbs écouter, avouer, discuter and chanter showed a significantly longer RTs than the mean of all verbs. The verbs balayer, piquer and vieillir showed significantly faster RTs than the mean of all verbs. The other verbs not shown in the graph showed RTs equal to the mean of the verbs. Right panel: random effect of participants on RTs. 


\section{SUPP. FIGURE 3}

\section{Temporal frames}

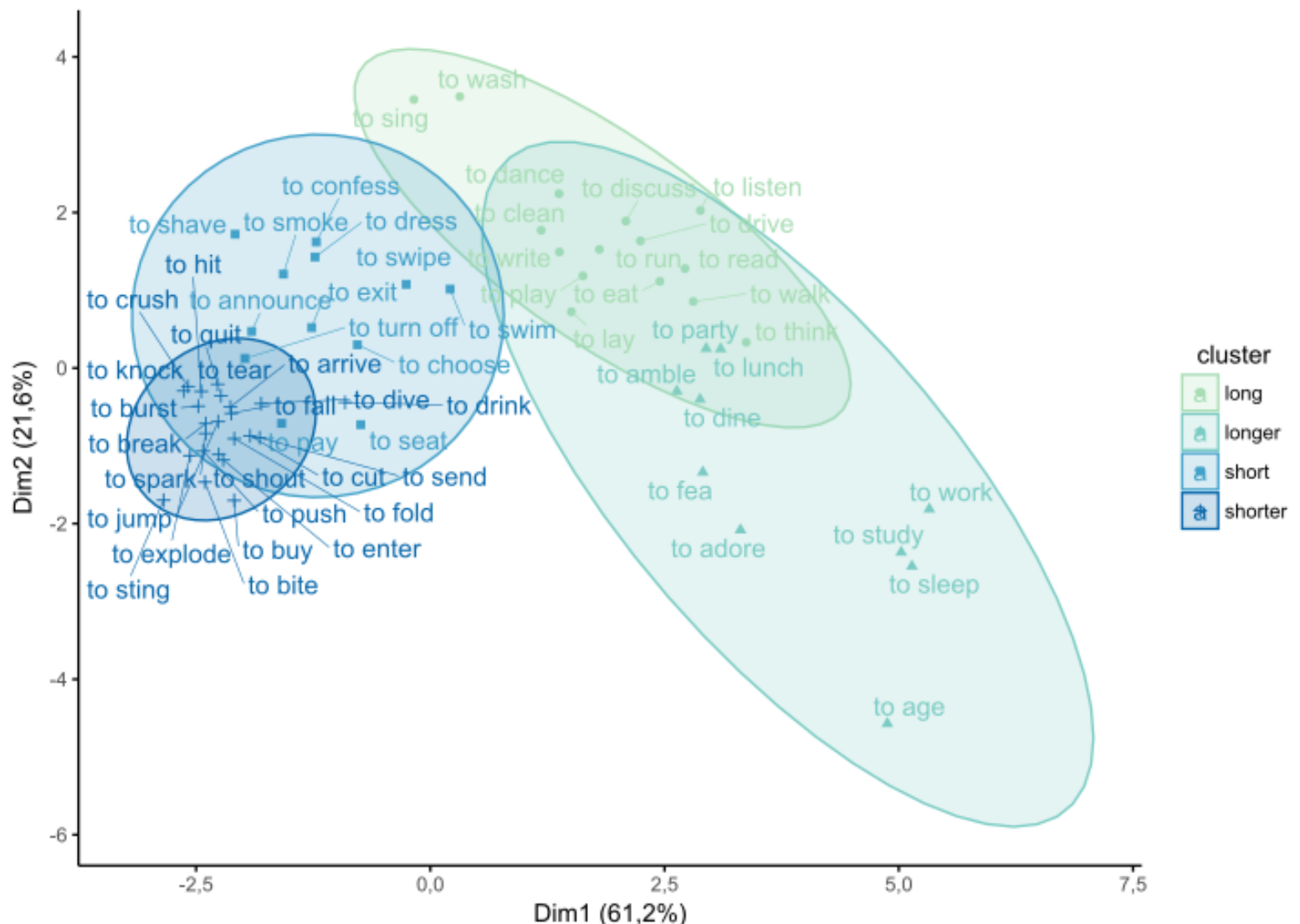

Supp. Figure 3: Suboptimal clustering in temporal categorization (tests 3 and 4). Temporal classification of verbs when considering a suboptimal case of 4 clusters. Although suboptimal, the classification of verbs is consistent with second, minute, hour and day timeframes. In line with the optimal two clusters, shortest verbs (e.g., mordre or sauter (to bite or to jump), in dark blue) are separated from longest verbs (e.g. vieillir or adorer (to age or to adore), turquoise). 
SUPP. TABLES

SUPP. TABLE 1

Test 1

Test 2

\begin{tabular}{|c|c|c|c|c|c|c|c|c|}
\hline \multirow{2}{*}{$\underbrace{\text { à priori }}_{\text {empirical }}$} & \multicolumn{2}{|c|}{ Punctual } & \multicolumn{2}{|c|}{ Durative } & \multicolumn{2}{|c|}{ Punctual } & \multicolumn{2}{|c|}{ Durative } \\
\hline & $\mathrm{N}$ & $\%$ & $\mathrm{~N}$ & $\%$ & $\mathrm{~N}$ & $\%$ & $\mathrm{~N}$ & $\%$ \\
\hline Missed & 8 & 0.37 & 11 & 0.51 & 7 & 0.32 & 7 & 0.32 \\
\hline Punctual & 1851 & 85.96 & 482 & 22.34 & 1853 & 85.79 & 467 & 21.62 \\
\hline Durative & 301 & 13.94 & 1667 & 77.18 & 300 & 13.89 & 1686 & 78.06 \\
\hline
\end{tabular}

Supp. Table 1: Descriptive Analysis of Aspectual Categorization (Tests 1 and 2). Data were gathered across all six series of aspectual categorizations.

SUPP. TABLE 2

\begin{tabular}{|c|c|c|c|c|c|c|c|}
\hline & $\begin{array}{l}\text { à priori } \\
\text { category }\end{array}$ & $\begin{array}{l}\text { Empirical } \\
\text { Classification }\end{array}$ & $\boldsymbol{\beta}$ & $\begin{array}{l}\text { S.E.M. } \\
\text { ( } \beta \text { ) }\end{array}$ & $\begin{array}{l}\operatorname{Exp} \\
(\beta)\end{array}$ & C.I. - 95\% & $P$ value \\
\hline \multirow{4}{*}{ 吾 } & \multirow{2}{*}{ Punctual } & Durative & - & - & 1 & - & - \\
\hline & & Punctual & -0.12 & 0.05 & 0.89 & {$[0.81 ; 0.97]$} & $0.011 *$ \\
\hline & \multirow{2}{*}{ Durative } & Punctual & - & - & 1 & - & - \\
\hline & & Durative & -0.11 & 0.04 & 0.89 & {$[0.83 ; 0.97]$} & $0.004 * *$ \\
\hline \multirow{5}{*}{ 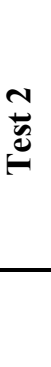 } & \multirow{2}{*}{ Punctual } & Durative & - & - & 1 & - & - \\
\hline & & Punctual & -0.09 & .05 & 0.91 & {$[0.83 ; 1.00]$} & 0.054 \\
\hline & \multirow{2}{*}{ Durative } & Punctual & - & - & 1 & - & - \\
\hline & & Durative & 0.04 & 0.04 & 1.04 & {$[0.96 ; 1.12]$} & 0.352 \\
\hline & $\begin{array}{l}\text { Empirical } \\
\text { Classification }\end{array}$ & Test & $\boldsymbol{\beta}$ & $\begin{array}{l}\text { S.E.M. } \\
(\boldsymbol{\beta})\end{array}$ & $\begin{array}{l}\operatorname{Exp} \\
(\beta)\end{array}$ & C.I. - 95\% & $P$ value \\
\hline \multirow{4}{*}{ 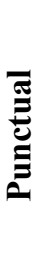 } & \multirow{2}{*}{ Punctual } & Test 1 & - & - & 1 & - & - \\
\hline & & Test 2 & -0.1 & 0.02 & 0.9 & {$[0.86 ; 0.94]$} & $0.000 * * *$ \\
\hline & \multirow{2}{*}{ Durative } & Test 1 & - & - & 1 & - & - \\
\hline & & Test 2 & -0.13 & 0.06 & 0.88 & {$[0.78 ; 0.98]$} & $0.025^{*}$ \\
\hline \multirow{4}{*}{ 胥 } & \multirow{2}{*}{ Punctual } & Test 1 & - & - & 0.1 & - & - \\
\hline & & Test 2 & -0.22 & 0.05 & 0.8 & {$[0.73 ; 0.88]$} & $0.000 * * *$ \\
\hline & \multirow{2}{*}{ Durative } & Test 1 & - & - & 1 & - & - \\
\hline & & Test 2 & -0.07 & 0.03 & 0.93 & {$[0.89 ; 0.98]$} & $0.006 * *$ \\
\hline
\end{tabular}

Supp. Table 2: Factors influencing RTs in Aspectual Categorization. Data were gathered across all six series and provide the adjustment of the log-linear model with random effects for responses collected in tests 1 and 2. S.E.M are standard errors to the means; C.I. are confidence intervals. 
SUPP. TABLE 3

\begin{tabular}{|c|c|c|c|c|c|c|}
\hline \multirow{2}{*}{ Categorization } & \multirow{2}{*}{ / Groups } & \multicolumn{2}{|c|}{ Punctual $(n=32)$} & \multicolumn{2}{|c|}{ Durative $(n=28)$} & \multirow{2}{*}{$\begin{array}{l}\text { Value-p } \\
\text { Mann-Whitney }\end{array}$} \\
\hline & & Mean & S.D. & Mean & S.D. & \\
\hline \multirow{2}{*}{$\%$ Punctual } & Test 1 & $84.4 \%$ & $10.9 \%$ & $19.6 \%$ & $13.2 \%$ & 0.000 \\
\hline & Test 2 & $84.5 \%$ & $11.6 \%$ & $18.8 \%$ & $12.8 \%$ & 0.000 \\
\hline \multirow{2}{*}{$\%$ Durative } & Test 1 & $15.6 \%$ & $10.9 \%$ & $80.4 \%$ & $13.2 \%$ & 0.000 \\
\hline & Test 2 & $15.5 \%$ & $11.6 \%$ & $81.2 \%$ & $12.8 \%$ & 0.000 \\
\hline \multirow{2}{*}{ Mean RTs } & Test 1 & 1.24 & 0.18 & 1.29 & 0.16 & 0.118 \\
\hline & Test 2 & 1.09 & 0.12 & 1.15 & 0.16 & 0.032 \\
\hline
\end{tabular}

Supp. Table 3: Analysis of cluster characterization for Aspectual categorization.

\section{SUPP. TABLE 4}

\begin{tabular}{|c|c|c|c|c|c|c|c|c|c|}
\hline \multirow[b]{2}{*}{ Verb } & \multicolumn{2}{|c|}{$\%$ Punctual } & \multicolumn{2}{|c|}{$\%$ Durative } & \multicolumn{2}{|c|}{ Mean RTs (s) } & \multicolumn{3}{|c|}{ Cluster analysis } \\
\hline & Test 1 & Test 2 & Test 1 & Test 2 & Test 1 & Test 2 & $\begin{array}{l}\text { D.F. } \\
\text { Punctual }^{1}\end{array}$ & $\begin{array}{l}\text { D.F. } \\
\text { Durative }\end{array}$ & $\begin{array}{l}\text { Best } \\
\text { classification }\end{array}$ \\
\hline asseoir & $80.6 \%$ & $75.0 \%$ & $19.4 \%$ & $25.0 \%$ & 1.43 & 1.22 & 0.94 & 0.06 & Punctual \\
\hline éteindre & $94.4 \%$ & $98.6 \%$ & $5.6 \%$ & $1.4 \%$ & 1.08 & 0.95 & 0.97 & 0.03 & Punctual \\
\hline coucher & $52.1 \%$ & $47.2 \%$ & $47.9 \%$ & $52.8 \%$ & 1.38 & 1.39 & 0.42 & 0.58 & Durative \\
\hline tomber & $88.9 \%$ & $85.9 \%$ & $11.1 \%$ & $14.1 \%$ & 1.11 & 1.02 & 0.99 & 0.01 & Punctual \\
\hline exploser & $95.8 \%$ & $98.6 \%$ & $4.2 \%$ & $1.4 \%$ & 1.26 & 1.00 & 0.98 & 0.02 & Punctual \\
\hline annoncer & $73.6 \%$ & $76.4 \%$ & $26.4 \%$ & $23.6 \%$ & 1.20 & 1.08 & 0.97 & 0.03 & Punctual \\
\hline payer & $87.5 \%$ & $90.3 \%$ & $12.5 \%$ & $9.7 \%$ & 1.12 & 1.05 & 0.99 & 0.01 & Punctual \\
\hline cogner & $94.4 \%$ & $93.1 \%$ & $5.6 \%$ & $6.9 \%$ & 1.03 & 1.00 & 0.97 & 0.03 & Punctual \\
\hline mordre & $86.1 \%$ & $87.5 \%$ & $13.9 \%$ & $12.5 \%$ & 1.09 & 0.94 & 0.98 & 0.02 & Punctual \\
\hline écraser & $87.5 \%$ & $84.7 \%$ & $12.5 \%$ & $15.3 \%$ & 1.43 & 1.13 & 0.98 & 0.02 & Punctual \\
\hline couper & $88.7 \%$ & $90.0 \%$ & $11.3 \%$ & $10.0 \%$ & 1.26 & 1.00 & 0.99 & 0.01 & Punctual \\
\hline sauter & $91.7 \%$ & $90.3 \%$ & $8.3 \%$ & $9.7 \%$ & 1.17 & 1.11 & 0.99 & 0.01 & Punctual \\
\hline avouer & $75.0 \%$ & $72.2 \%$ & $25.0 \%$ & $27.8 \%$ & 1.71 & 1.24 & 0.82 & 0.18 & Punctual \\
\hline piquer & $95.8 \%$ & $94.4 \%$ & $4.2 \%$ & $5.6 \%$ & 0.98 & 1.01 & 0.96 & 0.04 & Punctual \\
\hline casser & $94.4 \%$ & $95.8 \%$ & $5.6 \%$ & $4.2 \%$ & 1.06 & 0.96 & 0.97 & 0.03 & Punctual \\
\hline plonger & $81.7 \%$ & $83.3 \%$ & $18.3 \%$ & $16.7 \%$ & 1.25 & 1.28 & 0.97 & 0.03 & Punctual \\
\hline allumer & $93.1 \%$ & $93.1 \%$ & $6.9 \%$ & $6.9 \%$ & 1.18 & 1.17 & 0.99 & 0.01 & Punctual \\
\hline entrer & $90.1 \%$ & $86.1 \%$ & $9.9 \%$ & $13.9 \%$ & 1.16 & 1.08 & 1.00 & 0.00 & Punctual \\
\hline frapper & $91.5 \%$ & $93.1 \%$ & $8.5 \%$ & $6.9 \%$ & 1.13 & 0.99 & 0.98 & 0.02 & Punctual \\
\hline choisir & $71.8 \%$ & $70.4 \%$ & $28.2 \%$ & $29.6 \%$ & 1.27 & 1.34 & 0.88 & 0.12 & Punctual \\
\hline quitter & $90.3 \%$ & $94.4 \%$ & $9.7 \%$ & $5.6 \%$ & 1.56 & 1.04 & 0.94 & 0.06 & Punctual \\
\hline arriver & $84.7 \%$ & $87.1 \%$ & $15.3 \%$ & $12.9 \%$ & 1.51 & 1.15 & 0.96 & 0.04 & Punctual \\
\hline sortir & $79.2 \%$ & $80.6 \%$ & $20.8 \%$ & $19.4 \%$ & 1.04 & 1.01 & 0.97 & 0.03 & Punctual \\
\hline acheter & $88.9 \%$ & $87.5 \%$ & $11.1 \%$ & $12.5 \%$ & 1.10 & 1.00 & 0.99 & 0.01 & Punctual \\
\hline envoyer & $86.1 \%$ & $88.7 \%$ & $13.9 \%$ & $11.3 \%$ & 1.60 & 1.29 & 0.92 & 0.08 & Punctual \\
\hline envoyer & $87.5 \%$ & $87.5 \%$ & $12.5 \%$ & $12.5 \%$ & 1.11 & 1.32 & 0.97 & 0.03 & Punctual \\
\hline plier & $75.0 \%$ & $81.9 \%$ & $25.0 \%$ & $18.1 \%$ & 1.15 & 0.97 & 0.97 & 0.03 & Punctual \\
\hline crier & $87.3 \%$ & $86.1 \%$ & $12.7 \%$ & $13.9 \%$ & 1.10 & 0.98 & 0.99 & 0.01 & Punctual \\
\hline déchirer & $88.9 \%$ & $86.1 \%$ & $11.1 \%$ & $13.9 \%$ & 1.36 & 1.06 & 0.99 & 0.01 & Punctual \\
\hline éclater & $97.2 \%$ & $95.8 \%$ & $2.8 \%$ & $4.2 \%$ & 1.16 & 0.98 & 0.98 & 0.02 & Punctual \\
\hline promener & $8.3 \%$ & $12.5 \%$ & $91.7 \%$ & $87.5 \%$ & 1.25 & 1.17 & 0.01 & 0.99 & Durative \\
\hline habiller & $51.4 \%$ & $48.6 \%$ & $48.6 \%$ & $51.4 \%$ & 1.37 & 1.22 & 0.43 & 0.57 & Durative \\
\hline discuter & $15.5 \%$ & $6.9 \%$ & $84.5 \%$ & $93.1 \%$ & 1.46 & 1.36 & 0.04 & 0.96 & Durative \\
\hline conduire & $12.7 \%$ & $9.7 \%$ & $87.3 \%$ & $90.3 \%$ & 1.17 & 1.22 & 0.02 & 0.98 & Durative \\
\hline
\end{tabular}




\begin{tabular}{lll|ll|ll|lll} 
déjeuner & $18.1 \%$ & $12.5 \%$ & $81.9 \%$ & $87.5 \%$ & 1.26 & 1.06 & 0.01 & 0.99 & Durative \\
vieillir & $0.0 \%$ & $1.4 \%$ & $100.0 \%$ & $98.6 \%$ & 0.98 & 0.79 & 0.10 & 0.90 & Durative \\
courir & $11.1 \%$ & $8.3 \%$ & $88.9 \%$ & $91.7 \%$ & 1.27 & 1.24 & 0.02 & 0.98 & Durative \\
marcher & $9.7 \%$ & $6.9 \%$ & $90.3 \%$ & $93.1 \%$ & 1.19 & 1.15 & 0.02 & 0.98 & Durative \\
craindre & $27.8 \%$ & $31.9 \%$ & $72.2 \%$ & $68.1 \%$ & 1.36 & 0.99 & 0.07 & 0.93 & Durative \\
raser & $58.3 \%$ & $56.9 \%$ & $41.7 \%$ & $43.1 \%$ & 1.23 & 1.12 & 0.67 & 0.33 & Punctual \\
dîner & $12.5 \%$ & $15.3 \%$ & $87.5 \%$ & $84.7 \%$ & 1.31 & 1.10 & 0.01 & 0.99 & Durative \\
balayer & $30.6 \%$ & $37.5 \%$ & $69.4 \%$ & $62.5 \%$ & 1.30 & 1.09 & 0.09 & 0.91 & Durative \\
écrire & $16.9 \%$ & $11.3 \%$ & $83.1 \%$ & $88.7 \%$ & 1.31 & 1.34 & 0.02 & 0.98 & Durative \\
chanter & $25.0 \%$ & $23.6 \%$ & $75.0 \%$ & $76.4 \%$ & 1.16 & 1.14 & 0.02 & 0.98 & Durative \\
travailler & $7.2 \%$ & $8.3 \%$ & $92.8 \%$ & $91.7 \%$ & 1.60 & 1.04 & 0.06 & 0.94 & Durative \\
nettoyer & $37.5 \%$ & $34.7 \%$ & $62.5 \%$ & $65.3 \%$ & 1.72 & 1.23 & 0.21 & 0.79 & Durative \\
penser & $12.5 \%$ & $15.3 \%$ & $87.5 \%$ & $84.7 \%$ & 1.18 & 1.12 & 0.01 & 0.99 & Durative \\
danser & $18.3 \%$ & $18.3 \%$ & $81.7 \%$ & $81.7 \%$ & 1.05 & 1.38 & 0.05 & 0.95 & Durative \\
boire & $58.3 \%$ & $62.5 \%$ & $41.7 \%$ & $37.5 \%$ & 1.46 & 1.10 & 0.71 & 0.29 & Punctual \\
laver & $36.6 \%$ & $33.3 \%$ & $63.4 \%$ & $66.7 \%$ & 1.47 & 1.22 & 0.12 & 0.88 & Durative \\
fêter & $22.2 \%$ & $25.0 \%$ & $77.8 \%$ & $75.0 \%$ & 1.34 & 1.07 & 0.01 & 0.99 & Durative \\
nager & $26.4 \%$ & $23.9 \%$ & $73.6 \%$ & $76.1 \%$ & 1.28 & 1.05 & 0.02 & 0.98 & Durative \\
adorer & $20.8 \%$ & $21.1 \%$ & $79.2 \%$ & $78.9 \%$ & 1.25 & 1.22 & 0.01 & 0.99 & Durative \\
manger & $15.3 \%$ & $21.1 \%$ & $84.7 \%$ & $78.9 \%$ & 1.09 & 1.01 & 0.03 & 0.97 & Durative \\
écouter & $25.4 \%$ & $22.2 \%$ & $74.6 \%$ & $77.8 \%$ & 1.40 & 1.50 & 0.08 & 0.92 & Durative \\
dormir & $4.2 \%$ & $5.6 \%$ & $95.8 \%$ & $94.4 \%$ & 1.13 & 1.03 & 0.04 & 0.96 & Durative \\
fumer & $56.9 \%$ & $50.7 \%$ & $43.1 \%$ & $49.3 \%$ & 1.33 & 1.12 & 0.55 & 0.45 & Punctual \\
jouer & $20.8 \%$ & $15.3 \%$ & $79.2 \%$ & $84.7 \%$ & 1.22 & 1.06 & 0.01 & 0.99 & Durative \\
lire & $9.9 \%$ & $4.2 \%$ & $90.1 \%$ & $95.8 \%$ & 1.38 & 1.18 & 0.03 & 0.97 & Durative \\
étudier & $1.4 \%$ & $5.6 \%$ & $98.6 \%$ & $94.4 \%$ & 1.15 & 0.91 & 0.06 & 0.94 & Durative \\
\hline Supp. Tabbe
\end{tabular}

Supp. Table 4: Cluster analysis via Fuzzy c-means for Aspectual categorization. Best classification of the verb taking in consideration aspect and RTs.

\section{SUPP. TABLE 5}

\begin{tabular}{lcc|cc|cc}
\hline \multirow{2}{*}{ Categorization } & \multicolumn{2}{c|}{3} & \multicolumn{2}{|c|}{4} & \multicolumn{2}{c}{3 \& 4 } \\
\cline { 2 - 7 } & $\mathbf{N}$ & $\mathbf{0}$ & $\mathbf{N}$ & $\mathbf{\%}$ & $\mathbf{N}$ & $\%$ \\
\hline Missed & 15 & $0.35 \%$ & 20 & $0.46 \%$ & 35 & $0.41 \%$ \\
Second & 1238 & $28.66 \%$ & 1294 & $29.95 \%$ & 2532 & $29.31 \%$ \\
Minute & 1420 & $32.87 \%$ & 1397 & $32.34 \%$ & 2817 & $32.60 \%$ \\
Hour & 1138 & $26.34 \%$ & 1147 & $26.55 \%$ & 2285 & $26.45 \%$ \\
Day & 509 & $11.78 \%$ & 462 & $10.69 \%$ & 971 & $11.24 \%$ \\
\hline \hline
\end{tabular}

Supp. Table 5: Descriptive analysis of the temporal categorization (tests 3 and 4). 


\section{SUPP. TABLE 6}

\begin{tabular}{|c|c|c|c|c|c|c|}
\hline \multicolumn{2}{|c|}{ Temporal Categorization } & $\boldsymbol{\beta}$ & S.E.M. ( $\beta$ ) & $\operatorname{Exp}(\beta)$ & C.I. $-95 \%$ & P-value \\
\hline \multirow{4}{*}{ Test 3} & Second & - & - & 1,00 & - & - \\
\hline & Minute & -0.03 & 0.02 & 0.97 & {$[0.93 ; 1.01]$} & 0.172 \\
\hline & Hour & -0.03 & 0.03 & 0.97 & {$[0.93 ; 1.02]$} & 0.260 \\
\hline & Day & 0.12 & 0.03 & 1.12 & {$[1.05 ; 1.20]$} & $0.001 * * *$ \\
\hline \multirow{4}{*}{ Test 4} & Second & - & - & 1.00 & - & - \\
\hline & Minute & -0.03 & 0.02 & 0.97 & {$[0.93 ; 1.01]$} & 0.153 \\
\hline & Hour & -0.07 & 0.02 & 0.93 & {$[0.89 ; 0.98]$} & $0.003 * *$ \\
\hline & Day & 0.09 & 0.03 & 1.09 & {$[1.02 ; 1.17]$} & $0.011 * *$ \\
\hline \multirow{2}{*}{ Test 3} & Second & -0.10 & 0.00 & 0.90 & {$[0.90 ; 0.91]$} & $0.000 * * *$ \\
\hline & Minute & -0.11 & 0.01 & 0.90 & {$[0.89 ; 0.91]$} & $0.000 * * *$ \\
\hline \multirow{2}{*}{$\begin{array}{c}v s . \\
\text { Test } 4\end{array}$} & Hour & -0.13 & 0.01 & 0.88 & {$[0.87 ; 0.89]$} & $0.000 * * *$ \\
\hline & Day & -0.10 & 0.01 & 0.91 & {$[0.90 ; 0.92]$} & $0.000 * * *$ \\
\hline
\end{tabular}

Supp. Table 6: Factors significantly influencing RTs in Temporal Categorizations. A log-linear gamma model with random effects was used for RTs in temporal categorization tests 3 and test 4. S.E.M. are standard error to the means. C.I. are confidence intervals. Test 3 was significantly faster than test 4.

\section{SUPP. TABLE 7}

\begin{tabular}{|c|c|c|c|c|c|c|}
\hline \multirow{2}{*}{\multicolumn{2}{|c|}{ Categorization }} & \multicolumn{2}{|c|}{ Short $(n=32)$} & \multicolumn{2}{|c|}{ Long $(n=28)$} & \multirow{2}{*}{$\begin{array}{l}\text { p value } \\
\text { Mann-Whitney test }\end{array}$} \\
\hline & & Average & D.P. & Average & D.P. & \\
\hline \multirow{2}{*}{$\%$ Second } & Test 3 & $43.8 \%$ & $6.4 \%$ & $11.6 \%$ & $7.8 \%$ & $0.000 * * *$ \\
\hline & Test 4 & $44.3 \%$ & $6.0 \%$ & $13.8 \%$ & $8.1 \%$ & $0.000 * * *$ \\
\hline \multirow{2}{*}{$\%$ Minute } & Test 3 & $34.6 \%$ & $3.2 \%$ & $31.1 \%$ & $7.3 \%$ & 0.084 \\
\hline & Test 4 & $33.9 \%$ & $3.5 \%$ & $30.9 \%$ & $7.0 \%$ & 0.110 \\
\hline \multirow{2}{*}{$\%$ Hour } & Test 3 & $18.3 \%$ & $2.1 \%$ & $35.7 \%$ & $5.8 \%$ & $0.000 * * *$ \\
\hline & Test 4 & $18.5 \%$ & $2.5 \%$ & $36.0 \%$ & $5.9 \%$ & $0.000 * * *$ \\
\hline \multirow{2}{*}{ \% Day } & Test 3 & $3.3 \%$ & $2.9 \%$ & $21.6 \%$ & $12.2 \%$ & $0.000 * * *$ \\
\hline & Test 4 & $3.3 \%$ & $3.2 \%$ & $19.2 \%$ & $11.2 \%$ & $0.000 * * *$ \\
\hline \multirow{2}{*}{ Mean RTs } & Test 3 & 1.29 & 0.15 & 1.48 & 0.21 & $0.000 * * *$ \\
\hline & Test 4 & 1.13 & 0.11 & 1.29 & 0.19 & $0.000 * * *$ \\
\hline
\end{tabular}

Supp. Table 7: Temporal Categorization cluster. Log-linear gamma model with random effects was used for RTs in temporal categorization tests 3 and test 4 . Test 3 was significantly faster than test 4 . 


\begin{tabular}{|c|c|c|c|c|c|c|c|c|c|c|c|c|c|}
\hline \multirow[b]{2}{*}{ Verb } & \multicolumn{2}{|c|}{$\%$ Second } & \multicolumn{2}{|c|}{$\%$ Minute } & \multicolumn{2}{|c|}{ \% Hour } & \multicolumn{2}{|l|}{$\%$ Day } & \multicolumn{2}{|c|}{ Mean RT (s) } & \multicolumn{3}{|c|}{ Cluster analysis on duration } \\
\hline & Test 3 & Test 4 & Test 3 & Test 4 & Test 3 & Test 4 & Test 3 & Test 4 & Test 3 & Test 4 & $\begin{array}{c}\text { D.F. } \\
\text { Shorter }\end{array}$ & $\begin{array}{l}\text { D.F.L } \\
\text { onger }\end{array}$ & $\begin{array}{l}\text { Best } \\
\text { classification }\end{array}$ \\
\hline asseoir & $38.9 \%$ & $38.9 \%$ & $33.3 \%$ & $27.8 \%$ & $20.8 \%$ & $23.6 \%$ & $6.9 \%$ & $9.7 \%$ & 1.27 & 1.26 & 0.88 & 0.12 & Shorter \\
\hline éteindre & $47.9 \%$ & $48.6 \%$ & $32.4 \%$ & $33.3 \%$ & $18.3 \%$ & $15.3 \%$ & $1.4 \%$ & $2.8 \%$ & 1.43 & 1.35 & 0.80 & 0.20 & Shorter \\
\hline coucher & $18.1 \%$ & $21.4 \%$ & $33.3 \%$ & $30.0 \%$ & $31.9 \%$ & $30.0 \%$ & $16.7 \%$ & $18.6 \%$ & 1.56 & 1.35 & 0.08 & 0.92 & Longer \\
\hline tomber & $47.2 \%$ & $47.9 \%$ & $33.3 \%$ & $32.4 \%$ & $18.1 \%$ & $19.7 \%$ & $1.4 \%$ & $0.0 \%$ & 1.18 & 1.26 & 0.93 & 0.07 & Shorter \\
\hline exploser & $50.0 \%$ & $49.3 \%$ & $33.3 \%$ & $32.4 \%$ & $16.7 \%$ & $15.5 \%$ & $0.0 \%$ & $2.8 \%$ & 1.26 & 1.01 & 0.95 & 0.05 & Shorter \\
\hline annoncer & $40.3 \%$ & $41.7 \%$ & $37.5 \%$ & $36.1 \%$ & $19.4 \%$ & $19.4 \%$ & $2.8 \%$ & $2.8 \%$ & 1.32 & 1.26 & 0.92 & 0.08 & Shorter \\
\hline payer & $44.4 \%$ & $45.1 \%$ & $31.9 \%$ & $31.0 \%$ & $15.3 \%$ & $16.9 \%$ & $8.3 \%$ & $7.0 \%$ & 1.43 & 1.16 & 0.92 & 0.08 & Shorter \\
\hline cogner & $50.7 \%$ & $48.6 \%$ & $33.8 \%$ & $34.7 \%$ & $14.1 \%$ & $16.7 \%$ & $1.4 \%$ & $0.0 \%$ & 1.50 & 1.02 & 0.86 & 0.14 & Shorter \\
\hline mordre & $48.6 \%$ & $47.2 \%$ & $31.9 \%$ & $33.3 \%$ & $18.1 \%$ & $16.7 \%$ & $1.4 \%$ & $2.8 \%$ & 1.07 & 1.05 & 0.91 & 0.09 & Shorter \\
\hline écraser & $47.2 \%$ & $46.5 \%$ & $34.7 \%$ & $36.6 \%$ & $18.1 \%$ & $16.9 \%$ & $0.0 \%$ & $0.0 \%$ & 1.34 & 1.05 & 0.97 & 0.03 & Shorter \\
\hline couper & $48.6 \%$ & $47.2 \%$ & $31.9 \%$ & $30.6 \%$ & $16.7 \%$ & $18.1 \%$ & $2.8 \%$ & $4.2 \%$ & 1.29 & 1.20 & 0.97 & 0.03 & Shorter \\
\hline sauter & $50.0 \%$ & $47.2 \%$ & $31.9 \%$ & $33.3 \%$ & $16.7 \%$ & $18.1 \%$ & $1.4 \%$ & $1.4 \%$ & 1.32 & 1.12 & 0.98 & 0.02 & Shorter \\
\hline avouer & $38.9 \%$ & $38.9 \%$ & $36.1 \%$ & $36.1 \%$ & $16.7 \%$ & $16.7 \%$ & $8.3 \%$ & $8.3 \%$ & 1.90 & 1.30 & 0.48 & 0.52 & Longer \\
\hline piquer & $47.2 \%$ & $50.0 \%$ & $34.7 \%$ & $33.3 \%$ & $16.7 \%$ & $16.7 \%$ & $1.4 \%$ & $0.0 \%$ & 0.96 & 0.97 & 0.84 & 0.16 & Shorter \\
\hline casser & $47.1 \%$ & $48.6 \%$ & $34.3 \%$ & $32.9 \%$ & $18.6 \%$ & $17.1 \%$ & $0.0 \%$ & $1.4 \%$ & 1.28 & 1.06 & 0.98 & 0.02 & Shorter \\
\hline plonger & $44.4 \%$ & $45.8 \%$ & $33.3 \%$ & $31.9 \%$ & $19.4 \%$ & $19.4 \%$ & $2.8 \%$ & $2.8 \%$ & 1.31 & 1.20 & 0.98 & 0.02 & Shorter \\
\hline allumer & $47.2 \%$ & $48.6 \%$ & $31.9 \%$ & $34.7 \%$ & $18.1 \%$ & $16.7 \%$ & $2.8 \%$ & $0.0 \%$ & 1.26 & 1.05 & 0.98 & 0.02 & Shorter \\
\hline entrer & $45.1 \%$ & $44.4 \%$ & $33.8 \%$ & $33.3 \%$ & $18.3 \%$ & $19.4 \%$ & $2.8 \%$ & $2.8 \%$ & 1.18 & 0.96 & 0.92 & 0.08 & Shorter \\
\hline frapper & $45.1 \%$ & $47.9 \%$ & $35.2 \%$ & $35.2 \%$ & $19.7 \%$ & $15.5 \%$ & $0.0 \%$ & $1.4 \%$ & 1.28 & 1.12 & 0.99 & 0.01 & Shorter \\
\hline choisir & $34.7 \%$ & $38.9 \%$ & $34.7 \%$ & $31.9 \%$ & $18.1 \%$ & $18.1 \%$ & $12.5 \%$ & $11.1 \%$ & 1.56 & 1.30 & 0.61 & 0.39 & Shorter \\
\hline quitter & $48.6 \%$ & $47.2 \%$ & $33.3 \%$ & $34.7 \%$ & $16.7 \%$ & $16.7 \%$ & $1.4 \%$ & $1.4 \%$ & 1.26 & 1.30 & 0.92 & 0.08 & Shorter \\
\hline arriver & $43.1 \%$ & $44.4 \%$ & $34.7 \%$ & $34.7 \%$ & $19.4 \%$ & $19.4 \%$ & $2.8 \%$ & $1.4 \%$ & 1.27 & 1.04 & 0.98 & 0.02 & Shorter \\
\hline sortir & $40.0 \%$ & $40.3 \%$ & $34.3 \%$ & $33.3 \%$ & $20.0 \%$ & $22.2 \%$ & $5.7 \%$ & $4.2 \%$ & 1.65 & 1.15 & 0.63 & 0.37 & Shorter \\
\hline acheter & $45.8 \%$ & $45.8 \%$ & $33.3 \%$ & $30.6 \%$ & $15.3 \%$ & $16.7 \%$ & $5.6 \%$ & $6.9 \%$ & 1.12 & 1.02 & 0.93 & 0.07 & Shorter \\
\hline envoyer & $45.1 \%$ & $47.2 \%$ & $33.8 \%$ & $29.2 \%$ & $16.9 \%$ & $18.1 \%$ & $4.2 \%$ & $5.6 \%$ & 1.37 & 1.10 & 0.96 & 0.04 & Shorter \\
\hline appuyer & $50.0 \%$ & $47.1 \%$ & $31.9 \%$ & $34.3 \%$ & $16.7 \%$ & $17.1 \%$ & $1.4 \%$ & $1.4 \%$ & 1.09 & 1.17 & 0.92 & 0.08 & Shorter \\
\hline plier & $45.8 \%$ & $47.2 \%$ & $33.3 \%$ & $31.9 \%$ & $18.1 \%$ & $19.4 \%$ & $2.8 \%$ & $1.4 \%$ & 1.19 & 1.14 & 0.98 & 0.02 & Shorter \\
\hline crier & $47.2 \%$ & $50.0 \%$ & $33.3 \%$ & $30.6 \%$ & $18.1 \%$ & $18.1 \%$ & $1.4 \%$ & $1.4 \%$ & 1.23 & 1.07 & 0.97 & 0.03 & Shorter \\
\hline déchirer & $45.8 \%$ & $48.6 \%$ & $34.7 \%$ & $33.3 \%$ & $18.1 \%$ & $18.1 \%$ & $1.4 \%$ & $0.0 \%$ & 1.15 & 1.32 & 0.88 & 0.12 & Shorter \\
\hline éclater & $45.8 \%$ & $45.8 \%$ & $34.7 \%$ & $36.1 \%$ & $18.1 \%$ & $15.3 \%$ & $1.4 \%$ & $2.8 \%$ & 1.28 & 1.05 & 0.98 & 0.02 & Shorter \\
\hline promener & $7.0 \%$ & $9.7 \%$ & $32.4 \%$ & $27.8 \%$ & $38.0 \%$ & $45.8 \%$ & $22.5 \%$ & $16.7 \%$ & 1.35 & 1.02 & 0.24 & 0.76 & Longer \\
\hline habiller & $25.0 \%$ & $29.6 \%$ & $44.4 \%$ & $39.4 \%$ & $23.6 \%$ & $25.4 \%$ & $6.9 \%$ & $5.6 \%$ & 1.37 & 1.14 & 0.62 & 0.38 & Shorter \\
\hline discuter & $12.7 \%$ & $16.7 \%$ & $39.4 \%$ & $26.4 \%$ & $33.8 \%$ & $41.7 \%$ & $14.1 \%$ & $15.3 \%$ & 1.79 & 1.36 & 0.16 & 0.84 & Longer \\
\hline conduire & $11.1 \%$ & $11.1 \%$ & $30.6 \%$ & $36.1 \%$ & $38.9 \%$ & $41.7 \%$ & $19.4 \%$ & $11.1 \%$ & 1.69 & 1.23 & 0.10 & 0.90 & Longer \\
\hline déjeuner & $8.3 \%$ & $8.6 \%$ & $27.8 \%$ & $30.0 \%$ & $43.1 \%$ & $44.3 \%$ & $20.8 \%$ & $17.1 \%$ & 1.31 & 1.33 & 0.11 & 0.89 & Longer \\
\hline vieillir & $0.0 \%$ & $0.0 \%$ & $16.7 \%$ & $19.4 \%$ & $33.3 \%$ & $33.3 \%$ & $50.0 \%$ & $47.2 \%$ & 1.00 & 0.86 & 0.45 & 0.55 & Longer \\
\hline courir & $8.3 \%$ & $13.9 \%$ & $37.5 \%$ & $33.3 \%$ & $41.7 \%$ & $37.5 \%$ & $12.5 \%$ & $15.3 \%$ & 1.56 & 1.17 & 0.08 & 0.92 & Longer \\
\hline marcher & $8.5 \%$ & $5.6 \%$ & $32.4 \%$ & $31.9 \%$ & $39.4 \%$ & $40.3 \%$ & $19.7 \%$ & $22.2 \%$ & 1.42 & 1.33 & 0.04 & 0.96 & Longer \\
\hline craindre & $13.9 \%$ & $14.1 \%$ & $25.0 \%$ & $25.4 \%$ & $26.4 \%$ & $29.6 \%$ & $34.7 \%$ & $31.0 \%$ & 1.42 & 1.28 & 0.09 & 0.91 & Longer \\
\hline raser & $29.6 \%$ & $29.0 \%$ & $45.1 \%$ & $46.4 \%$ & $19.7 \%$ & $20.3 \%$ & $5.6 \%$ & $4.3 \%$ & 1.26 & 1.17 & 0.75 & 0.25 & Shorter \\
\hline dîner & $12.5 \%$ & $6.9 \%$ & $29.2 \%$ & $27.8 \%$ & $40.3 \%$ & $43.1 \%$ & $18.1 \%$ & $22.2 \%$ & 1.22 & 1.24 & 0.20 & 0.80 & Longer \\
\hline balayer & $15.3 \%$ & $19.4 \%$ & $43.1 \%$ & $40.3 \%$ & $31.9 \%$ & $31.9 \%$ & $9.7 \%$ & $8.3 \%$ & 1.22 & 1.00 & 0.48 & 0.52 & Longer \\
\hline écrire & $12.5 \%$ & $20.8 \%$ & $34.7 \%$ & $34.7 \%$ & $38.9 \%$ & $34.7 \%$ & $13.9 \%$ & $9.7 \%$ & 1.48 & 1.34 & 0.03 & 0.97 & Longer \\
\hline chanter & $20.8 \%$ & $23.6 \%$ & $41.7 \%$ & $43.1 \%$ & $30.6 \%$ & $30.6 \%$ & $6.9 \%$ & $2.8 \%$ & 1.71 & 1.45 & 0.22 & 0.78 & Longer \\
\hline travailler & $1.4 \%$ & $1.4 \%$ & $19.4 \%$ & $19.4 \%$ & $36.1 \%$ & $40.3 \%$ & $43.1 \%$ & $38.9 \%$ & 1.32 & 1.44 & 0.15 & 0.85 & Longer \\
\hline nettoyer & $18.1 \%$ & $19.4 \%$ & $36.1 \%$ & $34.7 \%$ & $34.7 \%$ & $33.3 \%$ & $11.1 \%$ & $12.5 \%$ & 1.44 & 1.52 & 0.15 & 0.85 & Longer \\
\hline penser & $8.3 \%$ & $12.5 \%$ & $29.2 \%$ & $25.0 \%$ & $33.3 \%$ & $31.9 \%$ & $29.2 \%$ & $30.6 \%$ & 1.72 & 1.42 & 0.12 & 0.88 & Longer \\
\hline danser & $15.3 \%$ & $18.1 \%$ & $34.7 \%$ & $36.1 \%$ & $37.5 \%$ & $38.9 \%$ & $12.5 \%$ & $6.9 \%$ & 1.81 & 1.22 & 0.19 & 0.81 & Longer \\
\hline boire & $33.3 \%$ & $30.6 \%$ & $36.1 \%$ & $34.7 \%$ & $22.2 \%$ & $22.2 \%$ & $8.3 \%$ & $12.5 \%$ & 1.18 & 1.11 & 0.86 & 0.14 & Shorter \\
\hline laver & $18.1 \%$ & $19.7 \%$ & $40.3 \%$ & $43.7 \%$ & $33.3 \%$ & $31.0 \%$ & $8.3 \%$ & $5.6 \%$ & 1.63 & 1.55 & 0.20 & 0.80 & Longer \\
\hline fêter & $5.6 \%$ & $9.7 \%$ & $29.2 \%$ & $30.6 \%$ & $41.7 \%$ & $37.5 \%$ & $23.6 \%$ & $22.2 \%$ & 1.54 & 1.13 & 0.10 & 0.90 & Longer \\
\hline nager & $16.7 \%$ & $19.4 \%$ & $38.9 \%$ & $38.9 \%$ & $34.7 \%$ & $33.3 \%$ & $9.7 \%$ & $8.3 \%$ & 1.27 & 1.08 & 0.38 & 0.62 & Longer \\
\hline adorer & $11.1 \%$ & $15.5 \%$ & $23.6 \%$ & $21.1 \%$ & $30.6 \%$ & $35.2 \%$ & $34.7 \%$ & $28.2 \%$ & 1.22 & 1.27 & 0.25 & 0.75 & Longer \\
\hline manger & $8.3 \%$ & $11.1 \%$ & $31.9 \%$ & $33.3 \%$ & $43.1 \%$ & $37.5 \%$ & $16.7 \%$ & $18.1 \%$ & 1.47 & 1.31 & 0.02 & 0.98 & Longer \\
\hline écouter & $12.5 \%$ & $13.9 \%$ & $26.4 \%$ & $34.7 \%$ & $36.1 \%$ & $34.7 \%$ & $25.0 \%$ & $16.7 \%$ & 1.69 & 1.75 & 0.24 & 0.76 & Longer \\
\hline dormir & $0.0 \%$ & $2.8 \%$ & $19.7 \%$ & $18.1 \%$ & $33.8 \%$ & $41.7 \%$ & $46.5 \%$ & $37.5 \%$ & 1.35 & 1.16 & 0.17 & 0.83 & Longer \\
\hline fumer & $31.9 \%$ & $33.3 \%$ & $40.3 \%$ & $40.3 \%$ & $22.2 \%$ & $22.2 \%$ & $5.6 \%$ & $4.2 \%$ & 1.49 & 1.07 & 0.69 & 0.31 & Shorter \\
\hline
\end{tabular}




\begin{tabular}{|c|c|c|c|c|c|c|c|c|c|c|c|c|c|}
\hline jouer & $12.5 \%$ & $15.3 \%$ & $36.1 \%$ & $33.3 \%$ & $34.7 \%$ & $36.1 \%$ & $16.7 \%$ & $15.3 \%$ & 1.44 & 1.32 & 0.02 & 0.98 & Longer \\
\hline lire & $8.3 \%$ & $15.3 \%$ & $29.2 \%$ & $31.9 \%$ & $43.1 \%$ & $37.5 \%$ & $19.4 \%$ & $15.3 \%$ & 1.52 & 1.48 & 0.08 & 0.92 & Longer \\
\hline étudier & $0.0 \%$ & $2.8 \%$ & $16.9 \%$ & $22.2 \%$ & $42.3 \%$ & $38.9 \%$ & $40.8 \%$ & $36.1 \%$ & 1.27 & 1.16 & 0.20 & 0.80 & Longer \\
\hline
\end{tabular}

Supp. Table 8: Cluster analysis via Fuzzy c-means for temporal categorization. Best classification of the verb taking in consideration timeframe and RTs.

\section{SUPP TABLE 9}

\begin{tabular}{lll|ll}
\hline \multirow{2}{*}{ Classification } & \multicolumn{2}{l|}{ Punctual } & \multicolumn{2}{l}{ Durative } \\
\cline { 2 - 5 } & $\mathbf{N}$ & $\mathbf{\%}$ & $\mathbf{N}$ & $\mathbf{\%}$ \\
\hline Missed & 19 & $0.88 \%$ & 20 & $0.93 \%$ \\
RT - (Mean); (S.D.) & $(2.63)$ & $(2.31)$ & $(3.18)$ & $(4.28)$ \\
\hline Shorter + Punctual & 1922 & $\mathbf{8 8 . 9 8 \%}$ & 717 & $33.19 \%$ \\
RT - (Mean); (S.D.) & $(1.28)$ & $(1.24)$ & $(1.63)$ & $(1.88)$ \\
\hline Longer + Durative & 219 & $10.14 \%$ & 1423 & $\mathbf{6 5 . 8 8 \%}$ \\
RT - (Mean); (S.D.) & $(1.62)$ & $(2.40)$ & $(1.45)$ & $(1.57)$ \\
\hline \hline
\end{tabular}

Supp. Table 9: Aspectual categorization given shorter / longer duration classification in Test 5.

\section{SUPP TABLE 10}

\begin{tabular}{lll|ll}
\hline \multirow{2}{*}{ Classification } & \multicolumn{2}{l|}{ Punctual } & \multicolumn{2}{c}{ Durative Verb } \\
\cline { 2 - 5 } & $\mathbf{N}$ & $\mathbf{\%}$ & $\mathbf{N}$ & $\%$ \\
\hline Missed & 38 & $1.76 \%$ & 21 & $0.97 \%$ \\
RT - (Mean); (S.D.) & $(2.62)$ & $(2.91)$ & $(3.33)$ & $(3.27)$ \\
\hline Longer duration + Punctual & 1114 & $51.57 \%$ & 1067 & $49.40 \%$ \\
RT - (Mean); (S.D.) & $(2.04)$ & $(2.91)$ & $(1.87)$ & $(2.25)$ \\
\hline Short duration + Durative & 1008 & $46.67 \%$ & 1072 & $49.63 \%$ \\
RT - (Mean); (S.D.) & $(2.02)$ & $(2.46)$ & $(1.94)$ & $(2.31)$ \\
\hline \hline
\end{tabular}

Supp. Table 10: Aspectual categorization given shorter / longer duration classification in Test 6. 